ARTICLE INFO

Received 03 April 2020

Accepted 10 June 2020

Available online June 2020

\title{
Methods of introducing poly- and perfluorinated fragments into a macromolecular system (REVIEW)
}

\author{
S. V. Kudashev \\ Volgograd State Technical University \\ 28 Lenin Avenue, Volgograd, Russia, 400005 \\ e-mail: kudashev-sv@yandex.ru
}

\begin{abstract}
The review is devoted to chemical and physical-chemical features of the introduction of poly- and perfluorinated compounds into macromolecular systems. Information about the properties and application value of fluoropolymers and polymer composite materials containing fluorinated fragments is summarized. This review consists of two parts. The first part discusses the achievements in the field of fluoropolymer chemistry and uses scientometric databases Scopus, Web of Science to conduct bibliometric and thematic analysis of publications. In the second part, the influence of poly- and perfluorinated compounds on the structure and properties of modified aliphatic polyamides, aromatic polyesters and polyurethanes depending on the method of introduction of the additive (modification of the polymer at the stage of its preparation, processing, surface modification of finished products) is considered. The prospects of creating fluorinecontaining composite and nanocomposite materials containing poly- and perfluorinated compounds immobilized on a highly dispersed carrier are noted. Bibliography of 184 references.
\end{abstract}

Keywords: fluoropolymers, polyfluorinated compounds, perfluorinated compounds, fluorine, polyfluorinated alcohols, heterocain polymers, modification, structure, properties, montmorillonite, carrier, immobilization, composite materials, nanocomposites.

\section{Content}

Introduction.

1. The state of fluoropolymers in the world market: development prospects, manufacturers and scientific schools.

2. Bibliometric analysis of publications on fluoropolymers using international scientometrical abstract databases. 
3. Introduction of poly- and perfluorinated compounds into macromolecular systems at the stage of production of aliphatic polyamides, aromatic polyesters and polyurethanes.

4. Introduction of poly- and perfluorinated compounds into macromolecular systems at the stage of processing aliphatic polyamides, aromatic polyesters and polyurethanes. Surface modification of polymeric materials by poly- and perfluorinated compounds.

5. Polymer composite materials containing poly- and perfluorinated compounds immobilized at a carrier.

Conclusions.

\section{Introduction}

The unique properties of fluorinated polymer materials put them forward among the leading priority research areas for solving a wide range of problems that determine the development of domestic and world-wide polymer industry [1-6]. The production and consumption of fluoropolymers and fluoropolymer composites is constantly expanding due to increasing needs of various sectors of economy. Distinctive features of most fluorine-containing materials are high heat resistance, chemical and biological inertness, weather resistance, good physical and mechanical properties, including abrasion resistance, reduced combustibility, and also - the acceptable dielectric properties [7-16].

Currently, the fluoropolymer materials on the world market are represented by products that are diverse in structure and properties [6, 9, 10, 17-19], namely:

- plastics, elastomers and elastoplasts;

- materials - insoluble, non-swellable and, conversely, soluble in solvents;

- radiation resistant fluoropolymer composites;

- threads and fibers with properties exceeding the strength of high alloy steel;

- films with unique dielectric- and electrical insulation properties that withstand the temperature of liquid hydrogen;

- fluororubber capable of operate under particularly harsh conditions;

- corrosion-resistant coatings with high barrier properties (low permeability to gases, vapors, moisture and other media) and resistant to weather impacts;

- perfluorinated homo- and copolymers for membrane gas separation (amorphous glassy teflons AF, Hyflon AD 40H, 40L and 60, Cytop). A specific feature of Hyflon fluoropolymers is their solubility in fluorinated solvents (Galden PFPE perfluoropolyesters and hydrofluoroethers), which provides uniform thin (less than $1000 \mathrm{~nm}$ ) polymer films. In addition, a change in mechanical and physicochemical properties of fluoropolymer is possible via introduction of perfluoropolyether lubricants (Fomblin PFPE) and their functionalized 
derivatives (Fluorolink PFPE).

The interest in fluorine-containing carbochain polymers originally arose in 1938, when the ability of tetrafluoroethylene to transform into chemically and thermally stable polytetrafluoroethylene was first discovered, which, however, had a number of significant disadvantages, namely - a low mechanical strength, cold flow and low radiation resistance [20, 21]. Over the next decade, a technical basis was created for production of fluorine-containing olefins (tetrafluoroethylene, vinyl and vinylidene fluorides, hexafluoropropylene and chlorotrifluoroethylene), polymers and copolymers. The obtained materials were successfully used in separation of uranium fluorides, as well as for creation of electronic devices (for high-altitude aviation, chemical industry) [20-22].

Since the 60 s of twenticent century, the attempts have been made to synthesize fluorinated hetero-chain polymers containing oxygen, nitrogen, sulfur, silicon and phosphorus atoms in the chain, with thermal stability exceeding the thermal stability of polytetrafluoroethylene, which promote to formation of fully separate research area - the chemistry of hetero-chain fluorinecontaining high-molecular compounds [23-28]. It should be noted that macromolecular systems in which fluorine atoms are directly bonded to carbon atoms are of the greatest practical interest.

The presence of polar groups in the chains of macromolecules significantly affects the supramolecular structure of a polymer, promouting to increase in intermolecular interaction, and leading to increase in the mechanical strength of materials. Improving the complex of properties of polymers can be achieved both by introducing individual fluorine atoms or small perfluorinated groups into their chains, and by using fully fluorinated monomers, which in some cases provide the maximum effect in improving the properties of materials.

Further development of chemical industry, machinery and aircraft, supersonic aviation, rocket and space technology, electronics, instrumentation and development of nuclear energy was already impossible to imagine without fluorinated polymers. The automotive, electrical, metallurgical, medical and petrochemical industries are also the consumers of fluoropolymers and composites based on them [29-32].

\section{The state of fluoropolymers in the world market: development prospects, manufacturers and scientific schools}

One of the key factors stimulating the development of fluoropolymers chemistry is the increasing demand of various industries for new materials (including fluorinated biopolymers, biodegradable and coordination fluoropolymers) that can work under conditions in which other polymers are not able to maintain their working efficiency. The development of chemistry and technology of fluorine-containing polymers and composites can be carried out in basically three 
ways: 1) synthesis of fluorine-containing monomers, 2) introduction of a fluorine-containing modifier at the stage of polymer production or processing and, finally, 3) surface modification of already synthesized polymer (granules) or products from it (filaments, films). A positive effect in changing the properties (or even acquiring new ones) of a polymer can be achieved using both polyfluorinated and perfluorinated compounds in micro quantities.

World leading companies such as Du Pont, Dongyue, Mitsubishi Chemical, 3M (Dyneon), Asahi Glass, Ohara Palladium Chemical Co., Sumitomo Chemical Co., Daikin, Gujarat, Solvay, AGC, Shanghai 3F, Juhua, Arkema, Kureha now produce the products of medium and low-tonnage chemistry (fluorinated oligomers and polymers, poly- and perfluorinated alkanes, esters, alcohols, acids, amines, ketones, heterocyclic compounds, etc.), using of which for processing materials based on carbo- and hetero-chain polymers allows give them dust-, water- and oil-repellent properties while maintaining the breathability. Thus, Daikin Global company has developed a wide range of fluoropolymers (Polyflon, Neoflon) characterized by high melt flow, particle size, softening temperature, electrical properties and service life.

In our country, the development the topic of fluoropolymers is obliged to the schools of academicians I. L. Knunyants, V. V. Korshak, N. A. Plate, A. V. Fokin, N. N. Vorozhtsov, V. M. Buznik, to the works of Z. A. Rogovin, V. A. Ponomarenko, B. F. Malichenko, K. A. Kocheshkov, A. Ya. Yakubovich, I. A. Gribova, A. P. Krasnov, A. I. Rakhimov, N. A. Adamenko and etc., as well as to the efforts of research teams in the of FSUE "VIAM" SSC RF, FSUE "RSC Applied Chemistry", Moscow State University n. a. M. V. Lomonosov, Volgograd State Technical University and Institutes of Russian Academy of Sciences: N. D. Zelinskii Institute of Organic Chemistry, Institute of Problems of Chemical Physics, A. N. Nesmeyanov Institute of Organoelement Compounds, A.V. Topchiev Institute of Fine Arts, A.N. Frumkin IHE, N.S. Kurnakov Institute of General Inorganic Chemistry, V. L. Talrose Institute of Chemistry (Far Eastern Branch of the Russian Academy of Sciences) and others. A series of valuable works in the field of chemistry of fluorine and fluoropolymers was carried out by G. Brown, O. Pierce, L. Wall, P. Tarrant, N. Bartlett, D. Sianesi, W. Mas-Grave and others [33-53].

Of special note is the contribution to development in fluoropolymer topic the "Center for Fluorine Chemistry - 21" (INEOS RAS) and the Consortium "Fluoropolymer Materials and Nanotechnologies", the main purpose of which is to increase the effectiveness of basic and applied research in the field of search, synthesis, modification of fluoropolymers, studies their properties and structure, expanding the areas of application of fluoropolymer materials, improving the production of fluoropolymer products and promoting their innovative implementation. This Consortium was created in 2007 in the form of a simple partnership (his coordinator was 
Academician of the Russian Academy of Sciences V. M. Buznik) and represents a base for interaction between researchers and manufacturers of fluoropolymers.

Very interesting are the development scenarios and dynamics of global and domestic fluoropolymer markets up to 2030, offered by various marketing studies (Roif Expert, Tebiz Group, Academy of Industrial Market Studies) [54, 55]. So, three stages of development are proposed: negative, inertial and innovative (see Table 1).

Table 1. The development forecast of Russian market of fluoropolymer according to the marketing study by Tebiz Group (in ths. tons).

\begin{tabular}{|c|c|c|c|c|c|c|}
\hline \multirow{2}{*}{ Indicator } & \multicolumn{2}{|c|}{ Negative scenario } & \multicolumn{2}{c|}{ Inertial scenario } & \multicolumn{2}{c|}{ Innovative scenario } \\
\cline { 2 - 7 } & $2020 \Gamma$. & $2021 \Gamma$. & $2020 \Gamma$. & $2021 \Gamma$. & $2020 \Gamma$. & $2021 \Gamma$. \\
\hline Production & 3779 & 3359 & 4210 & 3873 & 5051 & 4801 \\
\hline Import & 772 & 789 & 985 & 1064 & 1334 & 1522 \\
\hline Export & 4049 & 3788 & 4053 & 3880 & 3609 & 3416 \\
\hline Market size & 521 & 378 & 1184 & 1087 & 2827 & 2939 \\
\hline
\end{tabular}

Such countries as China (\$ 5 million), Italy (\$ 3.1 million) and Germany (\$ 2.2 million) in 2019 take the lead in the list of largest countries importing a fluoropolymers. Russian export supplies of fluoropolymers abroad during 2015-2019 increased by $41.95 \%$ (from $\$ 28.39$ to $\$ 40.3$ million). Among the Russian regions, the largest suppliers of fluoropolymer products in 2019 were the Kirov Region (52.6\% of the total supply), Perm Territory (41.36\%) and St. Petersburg (5.23\%), which formed in bulk $\$ 39,97$ million (see Tables $2-4$ ).

In Russia, the industrial production of fluorine-containing compounds is carried out by HaloPolymer JSC (Perm, Kirovo-Chepetsk), which is one of the largest manufacturers of fluoropolymer products, supplying to world market with at least $9 \%$ of total produced volume of fluoropolymer (over $80 \%$ of the volume domestic market). Pilot and industrial quantities of fluorine-containing compounds are supplied to the domestic market by PiM-Invest CJSC (Moscow Region) and some small innovative enterprises. 
Table 2. List of some Russian small innovative enterprises produced the fluoropolymer products.

\begin{tabular}{|c|c|}
\hline Enterprise Name & Type of fluoropolymer products and goods \\
\hline LLC SPE "Resource” (Krasnoyarsk) & Dry lubricant rods to reduce the wear of a pair "wheel/rails" for rail vehicles and bridge cranes \\
\hline LLC "Fluralit Synthesis" (Moscow) & Ultrafine fluoroplastic powders \\
\hline Institute of Chemistry FEB RAS (Vladivostok) & $\begin{array}{c}\text { Wide range of fluoroplastics products for use in various fields of technology, e.g. for lining of } \\
\text { pistons for car suspensions using compositions based on "Tefzel 750" with layered fillers; for lining } \\
\text { of chemical equipments by loose fluoroplastic liners }\end{array}$ \\
\hline LLC PCE "MITO” (Kirovo-Chepetsk) & $\begin{array}{r}\text { Bushings, o-rings made from composite fluoroplastics-based materials } \\
\hline \text { LLC “Technoplast (Yakutsk) }\end{array}$ \\
\hline
\end{tabular}


Table 3. Trademarks and world manufacturers of fiber-forming fluorine-containing polymeric materials [19].

\begin{tabular}{|c|c|c|c|}
\hline Trademark & Manufacturer & Composition & Types of fibers (threads) \\
\hline Teflon $^{*}$ & DuPont (USA) & \multirow{4}{*}{ Polytetrafluoroethylene } & \multirow[b]{2}{*}{$\begin{array}{l}\text { Multifilament yarns from a dispersed polytetrafluoroethylene in } \\
\text { viscose }\end{array}$} \\
\hline Polyphene & $\begin{array}{c}\text { OJSC SRI "Khimvolokno" } \\
\text { with experimental plant } \\
\text { (Russia) }\end{array}$ & & \\
\hline Gore-Tex & $\begin{array}{l}\text { W.L. Gore \& Associates } \\
\text { (Germany) }\end{array}$ & & $\begin{array}{l}\text { Threads and porous membranes obtained by molding from pastes } \\
\text { (by dispersion with lubricant) }\end{array}$ \\
\hline Lenzing Teflon & Lenzing AG (Austria) & & Fibrillated film threads obtained by planing of block blanks \\
\hline Teflon-FEP & DuPont (USA) & \multirow{3}{*}{$\begin{array}{l}\text { Tetrafluoroethylene/ } \\
\text { Hexafluoropropylene } \\
\text { Copolymer }\end{array}$} & \multirow{2}{*}{ Melt monofilament } \\
\hline Toyoflon-FEP & Toyobo Ltd (Japan) & & \\
\hline Fluorin & $\begin{array}{c}\text { OJSC SRI "Khimvolokno" } \\
\text { with experimental plant } \\
\text { (Russia) }\end{array}$ & & $\begin{array}{l}\text { Monofilament, multifilament yarn and staple fiber with high linear } \\
\text { density }\end{array}$ \\
\hline Tefcel-ETFE & \multirow{3}{*}{ Albany Int. (USA) } & Polytrifluoroethylene & Melt monofilament \\
\hline Halar-ECTFE & & Polytrifluorochlorethylene & Melt fibers \\
\hline Kynar & & Polyvinylidene Fluoride & Melt monofilament \\
\hline Ftorlon & $\begin{array}{l}\text { OJSC “Khimvolokno” } \\
\text { Serpukhov (Russia) }\end{array}$ & $\begin{array}{c}\text { Copolymer of } \\
\text { tetrafluoroethylene and vinyl } \\
\text { fluoride }\end{array}$ & Multifilament yarns, obtained by wet spinning from solutions \\
\hline
\end{tabular}

* The production of polytetrafluoroethylene fibers began in 1953. 
Table 4. Domestic industrial manufacturers of fluoropolymer products.

\begin{tabular}{|c|c|}
\hline Enterprise & Production \\
\hline JSC “Halopolimer” (Perm, Kirovo-Chepetsk) & $\begin{array}{l}\text { Wide range of fluoropolymers (from raw materials to products); fluoroplastic suspensions, } \\
\text { monomers, chladones, fluorocarbons, polyfluorinated telomeric alcohols }\end{array}$ \\
\hline OJSC "Plastpolymer" & Fluoroplastics, polyolefins, polystyrene plastics \\
\hline $\begin{array}{l}\text { FSUE VNII ARSSI “Aviation Materials” of SRC RF, } \\
\text { VIAM (Moscow) }\end{array}$ & $\begin{array}{l}\text { Development and pilot production of organoelemental fluorine-, sulfur-, silicon-containing } \\
\text { materials with fire- and heat-protective properties }\end{array}$ \\
\hline $\begin{aligned} \text { Corporate group "ChemPromSoyuz/EXPO-Kr" } \\
\text { (Moscow) }\end{aligned}$ & Fluoropolymers, products and blanks from fluoroplastics \\
\hline CJSC “Fluoroplastic technology”, (St. Petersburg) & Ftoroplastics products \\
\hline $\begin{array}{c}\text { Plastics recycling plant n.a. "Komsomolskaya Pravda" } \\
\text { (St. Petersburg) }\end{array}$ & Fluoroplastics and thermosets products \\
\hline LLC "Promarmatura" (Kirovo-Chepetsk) & $\begin{array}{l}\text { High-precision products made from fluoroplastics and various composites for mass and } \\
\text { exclusive consumers }\end{array}$ \\
\hline LLC “Kedron-Perm” (Perm) & $\begin{array}{l}\text { Production and delivery of precision products made from PTFE, polyamide, polyurethane } \\
\text { and compositions }\end{array}$ \\
\hline CJSC "Polyx + " (Kirovo-Chepetsk) & Fluoroplastics products \\
\hline LLC PCE “MITO” (Kirovo-Chepetsk) & A wide range of products made from fluoroplast- 4 for use in various fields of technology \\
\hline $\begin{array}{l}\text { OJSC Ural Chemical Company, "Uralchimplast" } \\
\text { (Nizhny Tagil) }\end{array}$ & Fluoroplastics products \\
\hline LLC “Constanta-2” (Volgograd) & Rubber rings with PTFE cover for severe operating conditions; PTFE seals \\
\hline
\end{tabular}




\section{Bibliometric analysis of publications on fluoropolymers using international scientometrical abstract databases}

Obtaining of new materials and creating advanced production technologies is impossible without scientific research, scientific and industrial cooperation and thorough analysis of publication statistics in the field of fluoropolymers. In scientific literature, attempts have already been made to bibliographic and thematic analysis of organofluorine compounds and fluoropolymers [53].

Academician of Russian Academy of Sciences V. M. Buznik and Ph.D. (education) I. V. Zibareva analyzed the world-wide dataset of scientific publications on fluoropolymers (over a period of 1946-2010) [56], as well as the bibliometric and thematic analysis of publications on fluorine chemistry (over a period of 1993-2014) [57] using «Chemical Abstracts Plus» database (CAS, USA), with access through the SciFinder system. As of December 2010, about 128 thousand publications were found using the term «fluoropolymers», with the largest number of publications (2000-2009) in the magazines «Macromolecules» (581 publications) and «High Molecular Compounds» (129 publications, among domestic journals). The number of world-wide and Russian patents during/over the specified period comprised to 48909 and 437, respectively.

The problematics of fluoropolymers were subjected of separate issues of magazines "High Molecular Compounds" (2013, Series A. vol. 55. No. 11) and "Russian Chemical Journal” (2008, vol. LII. No. 3), as well as the thematic conferences "Fluorine Chemistry" and "Fluoropolymers: Research, production problems, new applications". Special mention it should be noted the specialized journals "Fluorine notes" and "Journal of Fluorine Chemistry", devoted to theoretical and applied problems of fluorine chemistry.

Using abstract scientometric databases "Scopus" (the search by article title, short description, keywords), and "Web of Science", we carry-out the bibliometric analysis of scientific publications on fluoropolymers (the analysis by authors and type of publications, countries, organizations, branches of knowledge).

For the periods from 1964 to March 2020 (via "Scopus" database) and from 1975 to March 2020 (via "Web of Science") 4,963 and 2,203 documents were found, respectively, containing the controll term "fluoropolymers" as the main concept. As can be seen from Figure 1, there is a steady growth dynamics of publication activity on fluoropolymers. 

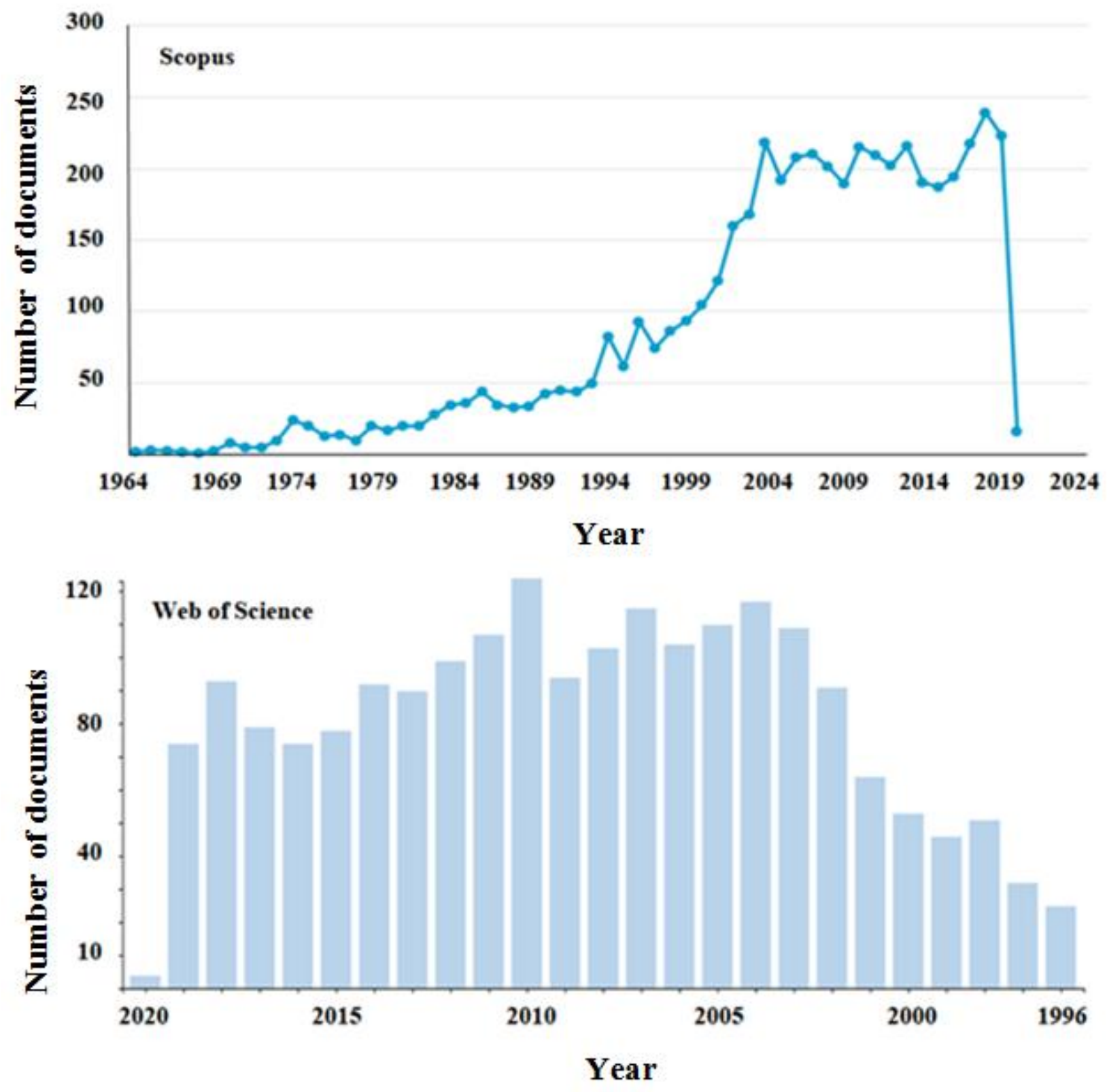

Figure 1. Dynamics of world publications in the field of fluoropolymers.

Distribution of documents (via "Scopus" databases) by type included articles (74.6\%), proceedings of conferences $(18.2 \%)$, reviews $(3.1 \%)$, chapters from books $(1.6 \%)$, books $(0.4 \%)$ and etc., which corresponded to the following branches of knowledge: materials science (28.1\%), chemistry (20.7\%), mechanical engineering (15.0\%), physics and astronomy (12.4\%), chemical engineering (9.1\%), environmental sciences (3.1\%), biochemistry, genetics and molecular biology (2.8\%) and the rest (8.7\%). Thus, the sources [2-15] should be considered as the most comprehensive synthesis of fluoropolymers.

The first ten authors with maximum number of publications are started by Ameduri B., Itani T., Boutevin B., Smith DW, Wooley KL, DeSimone JM, Kang ET, Neoh KG, Yamashita T, and 
Academician of Russian Academy of Sciences V. M. Buznik. Top the list of leading countries by number of publications on fluoropolymers of USA (1489 documents), China (608), Japan (503), Germany, France, Great Britain, Russian Federation (241 documents), Canada, Italy and South Korea. The following organizations are most active in the field of fluoropolymers: Du Pont (141 documents), Chinese Academy of Sciences (109 documents), Russian Academy of Sciences (94 documents), Ecole Nationale Supe'rieure de Chimie de Montpellier (ENSCM), Charles Gerhardt Institut Montpellier, CNRS Center National de la Recherche Scientifique, China Ministry of Education, AGC Inc., Semiconductor Leading Edge Technologies, Inc., Leibniz-Institut für Polymerforschung Dresden e.V.

According to the «Web of Science» database, the largest number of publications on fluoropolymers have authors Ameduri B. (95 records), Boutevin B. (38 records), DeSimone JM (36 records), Itani T., Smith DW, Wooley KL, Yamashita T., Hill DJT, Zhang ZC, Rinaldi PL and organizations (the search by “organization profiles") Center National de la Recherche Scientifique CNRS (122 records), Universite De Montpellier (94 records), Chinese Academy of Sciences (80 records), Du Pont (80 records) and Ecole Nationale Superieure de Chimie de Montpellier (74 records).

Patent analysis of world-wide publications on fluoropolymer topics is presented in Table 5. Thus, the leading patent offices are the United States Patent and Trademark Office, Japan Patent Office, European Patent Office, World Intellectual Property Organization and United Kingdom Intellectual Property Office.

According to the «Web of Science» database (found 55 records), the leaders by number of publications related to polyfluorinated alcohols are Volgograd State Technical University, Russian Academy of Sciences, N. D. Zelinskii Institute of Organic Chemistry, N. N. Vorozhtsov Institute on inorganic chemistry RAS (Novosybirsk) and Adam Mickiewicz University. According to the "Scopus" database (search by "documents on organization"), the first five places are occupied by the Volgograd State Technical University RAS, A. N. Nesmeyanov Institute of Organoelement Compounds RAS (USSR), Research Center for Eco-Environmental Sciences Chinese Academy of Sciences and Du Pont.

Table 5. Results of bibliometric analysis ("Scopus" databases) of a number of world-wide publications on various main concepts.

\begin{tabular}{|c|c|c|}
\hline Search by term & Search Results & Patents \\
\hline «fluoropolymers» & 4963 & 131971 \\
\hline «fluoropolymer composites» & 73 & 666 \\
\hline
\end{tabular}




\begin{tabular}{|c|c|c|}
\hline «fluorinated polymer» & 1503 & 41743 \\
\hline «fluorine-containing polymer» & 14408 & 36543 \\
\hline «polyfluorinated alcohols» & 66 & 117 \\
\hline «fluorinated alcohols» & 565 & 12780 \\
\hline «fluorinated polyamide» & 54 & 245 \\
\hline «fluorinated polyesters» & 33 & 480 \\
\hline «fluorinated polyurethanes» & 117 & 878 \\
\hline «fluorinated montmorillonite» & 9 & 54 \\
\hline
\end{tabular}

Thus, the conducted bibliometric analysis (primarily - by term "fluoropolymers") showed that currently research in the field of fluoropolymers is on a steady rise, with three leaders - USA, China and Japan. In terms of publication activity, the Russian Federation ranks 7 th in the ranking of countries (via "Scopus" databases) and 8th (via "Web of Science" database). Over a period of 1998 - January 2020, the number of world-wide publications on fluoropolymers increased 2.7 times. The growing number of patents on fluoropolymer topics reflects an obvious applied trend in research in this area. However, there is a noticeable absence of industrial leaders of national economy of Russia at forefront in global ratings for publications and patents, which, apparently, indicates a lack of cooperation between science and production.

\section{Introduction of poly- and perfluorinated compounds into macromolecular systems at the stage of production of aliphatic polyamides, aromatic polyesters and polyurethanes}

Fluorine-containing heterochain polymers can be synthesized by all methods used to obtain their non-fluorinated analogues. The development of new methods for introducing fluorine atoms into organic molecules led to the creation of a reliable foundation for development of fluoropolymers and tightest cooperation of synthetic organofluorine chemistry and chemistry of fluorine-containing high molecular weight compounds [8, 39, 41, 58-62].

First reports about synthesis of fluorine-containing polyamides appeared in 1951 (Olvelt's patent), polyesters - in 1952, and polyurethanes - in 1958. As of 1971, the industrial production of fluoropolyethers was already organized world-wide. The methods of production and characterization of fluorinated products are given in Tables 6-9 [23, 24, 28].

Fluorine atoms have a significant impact on the reactivity of monomers [61, 63]. For example, octafluoro- $\varepsilon$-caprolactam does not polymerize under conditions in which its nonfluorinated analog forms a high molecular weight product: 


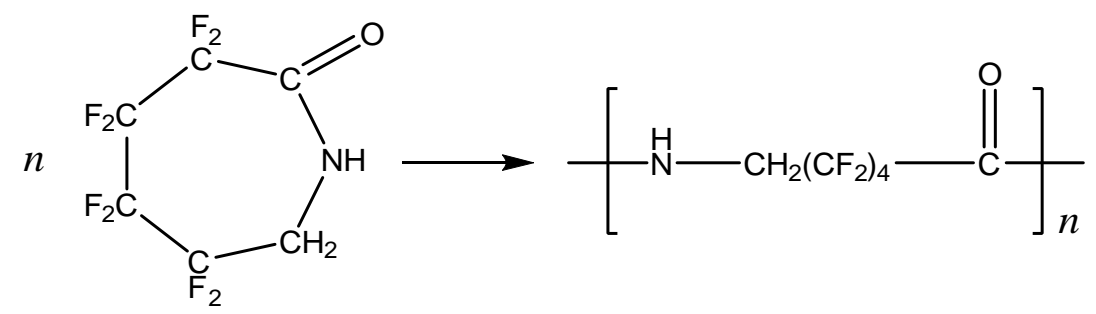

Oligo- and polymerization of $\varepsilon$-caprolactam (under catalysis with acetic acid, triethylamine, $\mathrm{N}, \mathrm{N}$-dimethylformamide, copper diacetate-di-e-caprolactamate, $p$-toluenesulfonic acid) in the presence of polyfluorinated alcohols leads to $10 \%$ content reduction of low molecular weight compounds and to increase viscosity of granulate [64-68]. Polyfluorinated alcohols react with $\varepsilon$ caprolactam according to scheme [65]:

Table 6. Some production process of fluorine-containing heterochain polymers.

\begin{tabular}{|c|c|}
\hline Fluoropolymer & Production process \\
\hline \multirow{4}{*}{$\begin{array}{l}\text { Fluorinated } \\
\text { polyamides }\end{array}$} & - Reaction of dicarboxylic acid and fluorinated primary diamine \\
\hline & $\begin{array}{l}\text { - Reaction of fluorinated dicarboxylic acid and non-fluorinated primary } \\
\text { diamine }\end{array}$ \\
\hline & $\begin{array}{l}\text { - Reaction of non-fluorinated dicarboxylic acid and fluorinated primary } \\
\text { diamine }\end{array}$ \\
\hline & - Reaction of fluorine-containing lactams polymerization \\
\hline \multirow{3}{*}{$\begin{array}{l}\text { Fluorinated } \\
\text { polyesters }\end{array}$} & - Direct esterification of diols with dicarboxylic acids (with $\mathrm{ZnCl}_{2}$ catalyst) \\
\hline & $\begin{array}{c}\text { - Transesterification of diols with diethyl ethers of dicarboxylic acids using } \\
\text { various catalysts }\end{array}$ \\
\hline & - Reaction of diols and dicarboxylic acid dichlorides \\
\hline \multirow{3}{*}{$\begin{array}{l}\text { Fluorinated } \\
\text { polyurethanes }\end{array}$} & $\begin{array}{l}\text { - Reaction of fluorinated diisocyanates (polyisocyanates) and non-fluorinated } \\
\text { diols }\end{array}$ \\
\hline & $\begin{array}{l}\text { - Reaction of non-fluorinated diisocyanates (polyisocyanates) and fluorinated } \\
\text { diols }\end{array}$ \\
\hline & - Reaction of fluorinated diisocyanates (polyisocyanates) and fluorinated diols \\
\hline
\end{tabular}

Table 7. Properties of some aliphatic fluorine-containing polyamides (interfacial polycondensation/equilibrium polycondensation).

\begin{tabular}{|c|c|c|}
\hline Chemical structure of elementary unit & Melting point, ${ }^{\circ} \mathrm{C}$ & $\begin{array}{c}\text { Reduced viscosity of a 0.5\% } \\
\text { solution of polyamide in DMF or } \\
\mathrm{H}_{2} \mathrm{SO}_{4} \text { (conc.) }\end{array}$ \\
\hline$-\mathrm{OC}\left(\mathrm{CF}_{2}\right)_{4} \mathrm{CONH}_{\left(\mathrm{CH}_{2}\right)_{6} \mathrm{NH}-}$ & $210-211 / 192-193$ & $0,238 / 0,084$ \\
\hline$-\mathrm{OC}\left(\mathrm{CF}_{2}\right)_{4} \mathrm{CONHCH}_{2}\left(\mathrm{CF}_{2}\right)_{4} \mathrm{CH}_{2} \mathrm{NH}-$ & $253 / 231-232$ & $0,108 / 0,030$ \\
\hline$-\mathrm{OC}\left(\mathrm{CH}_{2}\right)_{4} \mathrm{CONHCH}_{2}\left(\mathrm{CF}_{2}\right)_{4} \mathrm{CH}_{2} \mathrm{NH}-$ & $216-223 / 219-221$ & $0,211 / 0,030$ \\
\hline$-\mathrm{OC}\left(\mathrm{CF}_{2}\right)_{4} \mathrm{CONH}_{(}\left(\mathrm{CH}_{2}\right)_{8} \mathrm{NH}-$ & $175-180 /-$ & $0,205 /-$ \\
\hline
\end{tabular}


Table 8. Properties of some aromatic fluorinated polyesters (including polyarylates).

Characteristic properties*




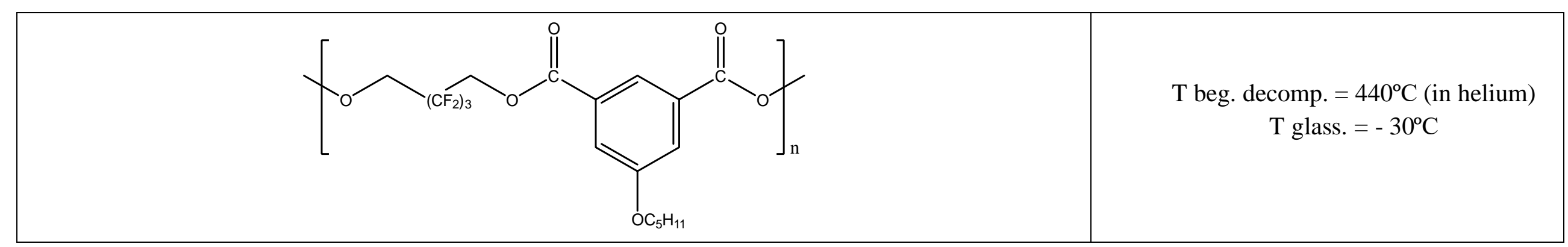

* hereinafter T soft is softening temperature; T decomp. - onset temperature; T glass. - glass transition temperature. 
Table 9. Properties of some aromatic fluorinated polyurethanes.

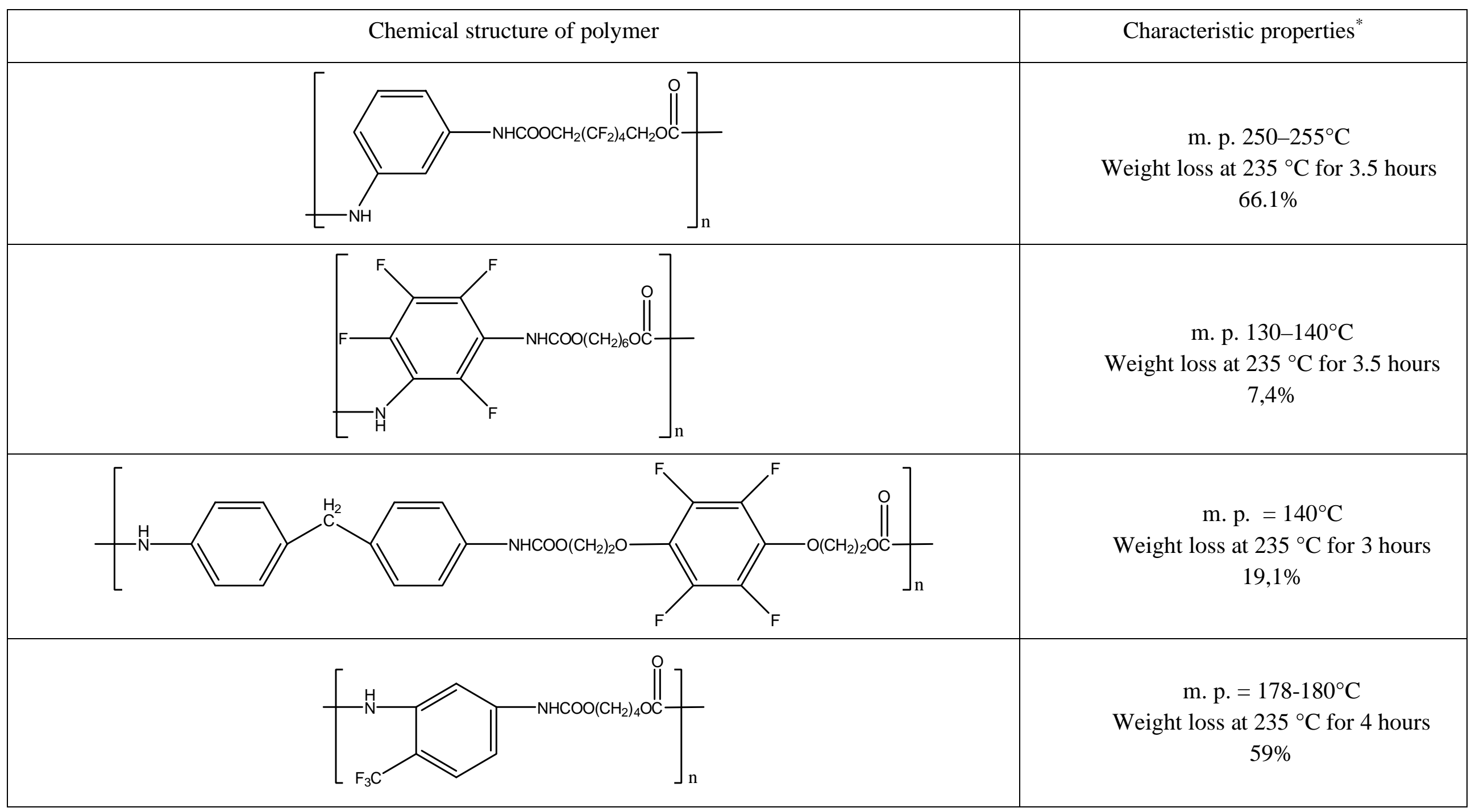




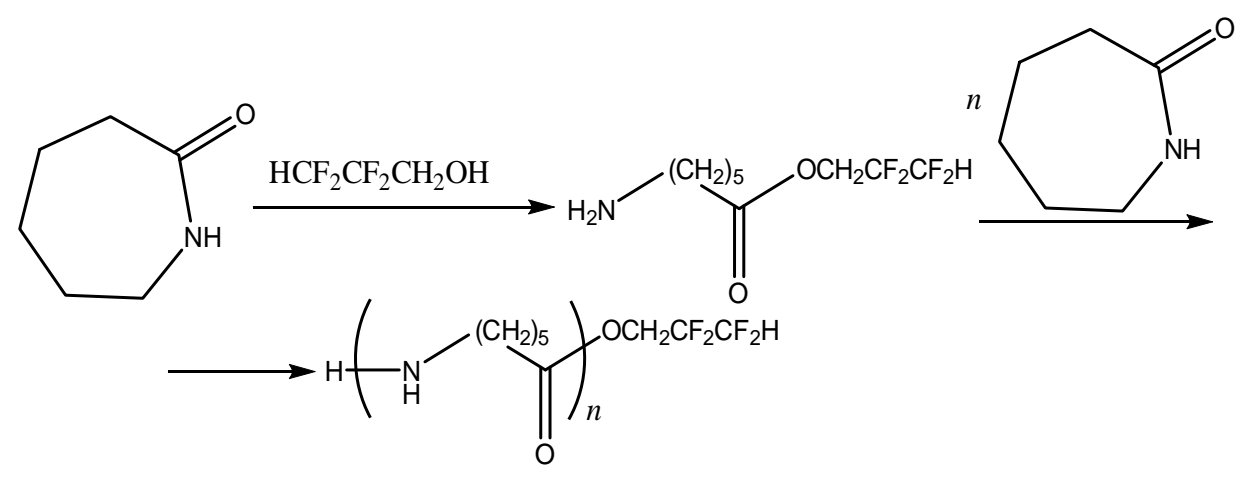

The influence of chemical structure of polyfluorinated alcohols $\mathrm{H}\left(\mathrm{CF}_{2} \mathrm{CF}_{2}\right)_{n} \mathrm{CH}_{2} \mathrm{OH}$ on composition and yields of resulting products was established: the reaction of alcohol $n=1$ with $\varepsilon^{-}$ caprolactam breaks off at $\mathrm{N}-(1 \mathrm{H}, 1 \mathrm{H}, 3 \mathrm{H}$-perfluoropropyl)-derivative of dimer (yield 39.6\%), and alcohol $n=2$ forms higher oligomers (yield 73.5\%). With a further increase in degree of telomerization of alcohol, the reaction slows down and the yield of oligomers decreases to $13.7 \%$ for $n=3$ and to $10.3 \%$ - for $n=4$. A set of alcohols reactivity was established, i.e.:

$$
n=1>n=2>>n=3 \text {. }
$$

$\mathrm{N}, \mathrm{N}$-dimethylformamide is a more active catalyst than triethylamine, and copper diacetatedi-e-caprolactamate is superior in efficiency. The properties of polycaproamide modified with polyfluorinated alcohols are presented in Table 10 [69].

Table 10. Impact of $8.8 \cdot 10^{-4} \% \mathrm{wt} .1 \mathrm{H}, 1 \mathrm{H}, \mathrm{H}$-perfluoropentan-1-ol (introduced at the stage of hydrolytic polymerization of $\varepsilon$-caprolactam) on physical and mechanical properties, and on heat resistance of polycaproamide fiber.

\begin{tabular}{|c|c|c|c|}
\hline Polyamide sample & Breaking load, $\mathrm{N}$ & Relative elongation, $\%$ & Residual strength, $\%$ \\
\hline Original & 125 & 16,0 & 80,3 \\
\hline Fluorine-containing & 134 & 15,3 & 85,7 \\
\hline
\end{tabular}

The possibility of obtaining aliphatic polyamides containing fluorinated groups with higher thermal stability and surface hydrophobicity was demonstrated in [70]. The modified polyamide was synthesized by anionic polymerization using perfluorobutyryl-substituted $\alpha$-amino- $\varepsilon$ caprolactam obtained as a fluorinated comonomer by condensation of $\alpha$-amino- $\varepsilon$-caprolactam and perfluorobutyryl chloride (at $20{ }^{\circ} \mathrm{C}$, in inert atmosphere, with triethylamine, tetrahydrofuran). The initiator and activator of polymerization were $\varepsilon$-caprolactamate sodium and N-carbamoylactam, respectively. The properties of the obtained polymers are shown in Table 11. 


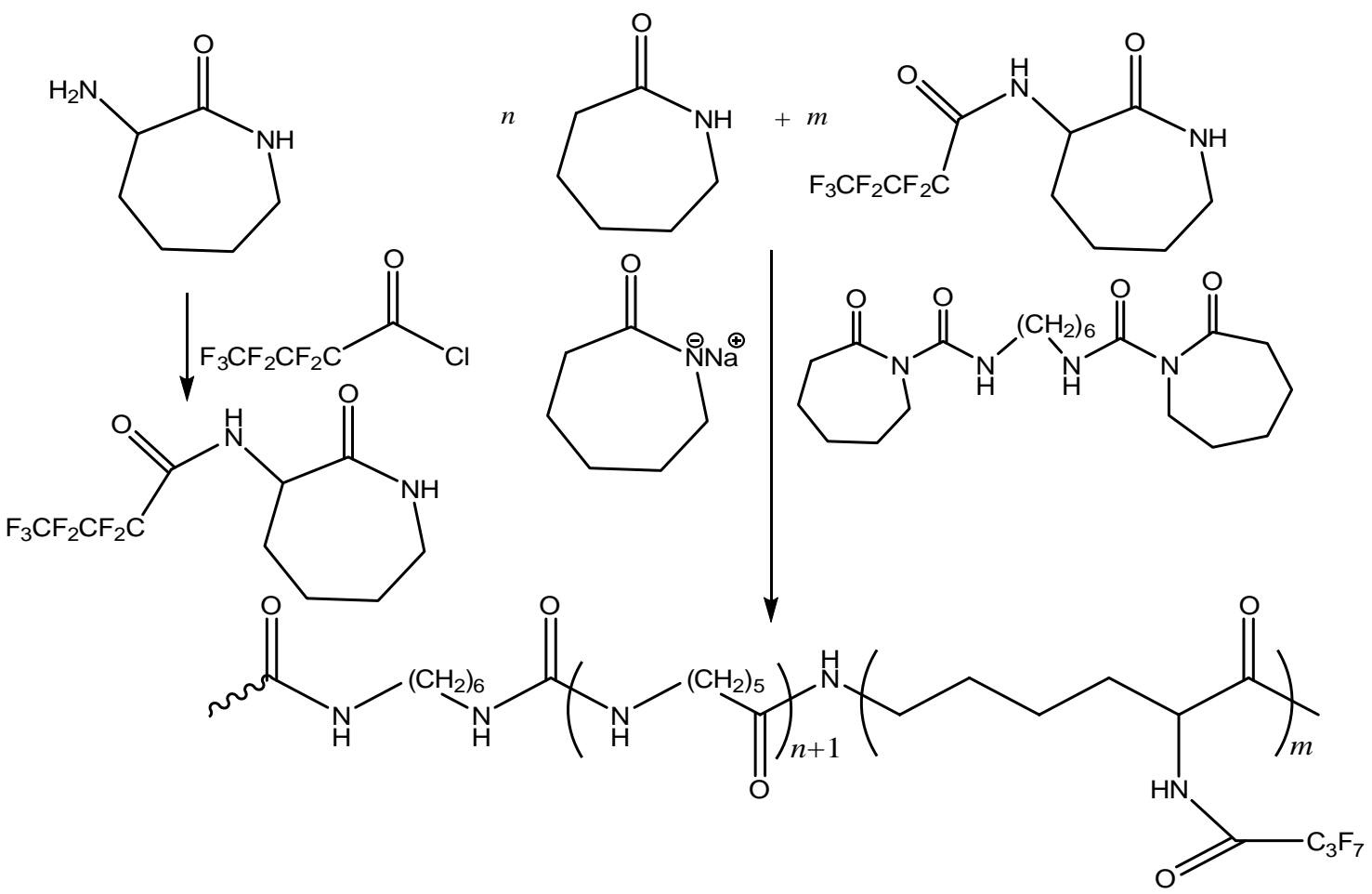

Table 11. Characteristic properties of aliphatic polyamides.

\begin{tabular}{|c|c|c|c|}
\hline \multirow{2}{*}{\begin{tabular}{c}
\multirow{2}{*}{$\begin{array}{c}\text { Polyamide } \\
\text { sample }\end{array}$} \\
\cline { 2 - 4 }
\end{tabular}} & $\begin{array}{c}\text { Melting point, } \\
{ }^{\circ} \mathrm{C}\end{array}$ & $\begin{array}{c}\text { Onset temperature of thermal } \\
\text { decomposition, }{ }^{\circ} \mathrm{C}\end{array}$ & $\begin{array}{c}\text { Surface energy, } \\
\mathrm{mN} \times \mathrm{cm}^{-1}\end{array}$ \\
\hline Original & 216 & 310 & 49,4 \\
\hline Fluorine-containing & 198 & 390 & 44,1 \\
\hline
\end{tabular}

Use of polyfluorinated alcohols $\mathrm{H}\left(\mathrm{CF}_{2} \mathrm{CF}_{2}\right)_{n} \mathrm{CH}_{2} \mathrm{OH}(\mathrm{n}=1-5)$ for synthesis of aromatic esters $\mathrm{C}_{6} \mathrm{H}_{6-m}\left[\mathrm{C}(=\mathrm{O})-\mathrm{O}-\mathrm{CH}_{2}\left(\mathrm{CF}_{2} \mathrm{CF}_{2}\right)_{n} \mathrm{H}\right]_{m}(m=3-4)$ helps to obtain the product, possessing a good oxidative stability at $205-316^{\circ} \mathrm{C}$, low volatility at $205^{\circ} \mathrm{C}$ and high lubricating properties [23]. The properties of polyesters synthesized using fluorinated diol $\mathrm{HOCH}_{2}-\left(\mathrm{CF}_{2}\right)_{3}-\mathrm{CH}_{2} \mathrm{OH}$ and aromatic acid dicarboxylic acids with various chemical structures are shown in Table 12 [23, 28]. 
Table 12. Characteristic properties of of aromatic polyesters containing O-polyfluoroalkyl fragments.

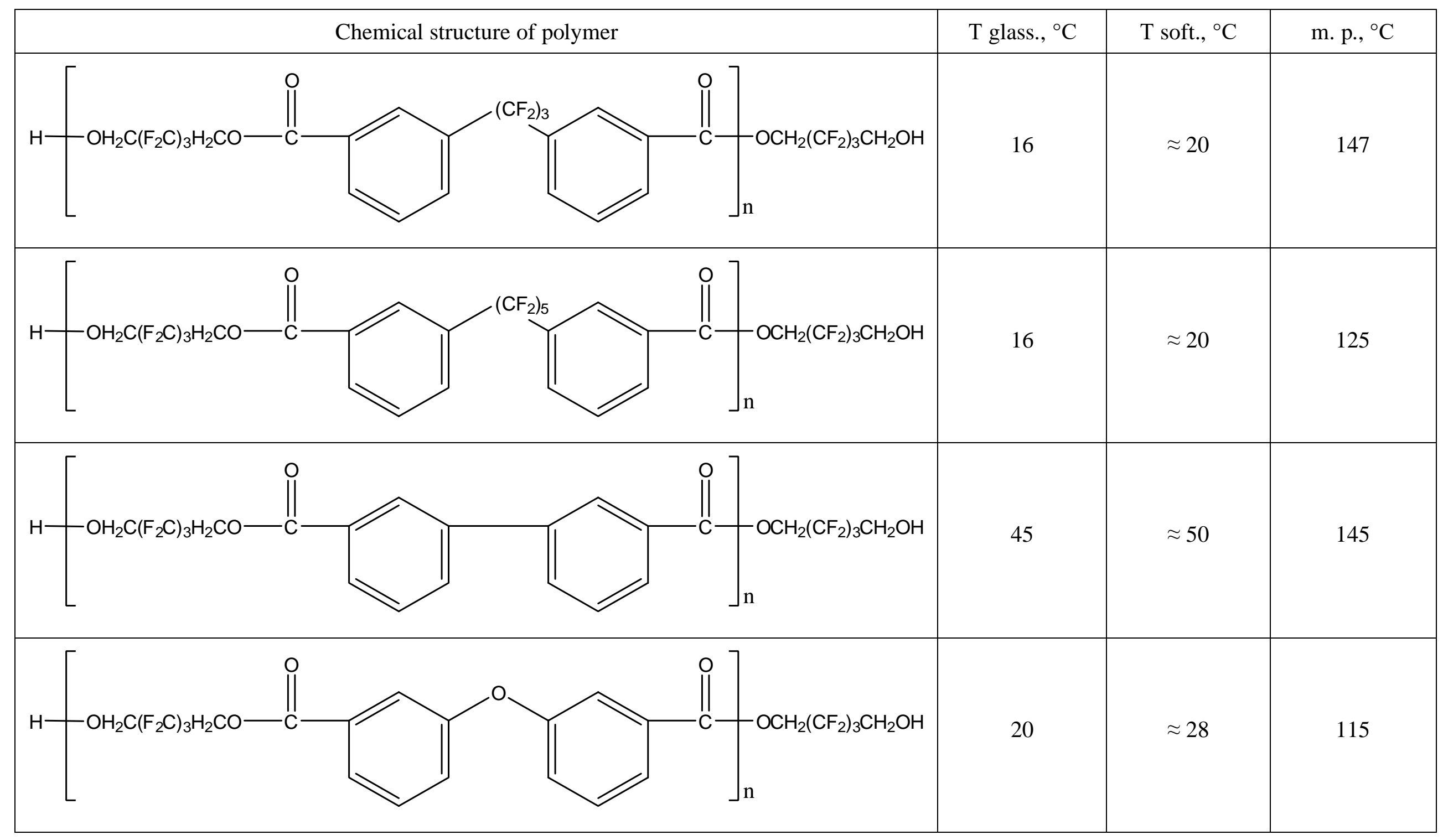


One of main disadvantages of non-fluorinated polyurethanes is their low thermal and hydrolytic stability. The $\mathrm{NH}-\mathrm{C}(=\mathrm{O})-\mathrm{O}-$ group breaks down at temperatures of about $200{ }^{\circ} \mathrm{C}$, and polyesters based polyurethanes are hydrolyze under the action of hot water, which jointly limits the field of practical use of these materials. When obtaining fluorine-containing polyurethanes, it is necessary to take into account that introducing $-\mathrm{CF}_{2}-\mathrm{NH}-\mathrm{C}(=\mathrm{O})-\mathrm{O}-$ groups into macromolecular chains is impractical because the elimination of HF occurs just with moderate heating and even under influence of air moisture [24].

The synthesis of fluorinated aromatic polyurethanes, as a rule, consists in the interaction of a fluorinated diol (for example, $\mathrm{HOCH}_{2}-\left(\mathrm{CF}_{2}\right)_{3}-\mathrm{CH}_{2} \mathrm{OH}$ with isocyanates [23, 24, 28]. In this case, fluorine can be contained in diol and (or) diisocyanate components. Fluoropolymers including $1 \mathrm{H}, 1 \mathrm{H}, 3 \mathrm{H}$-perfluoropropyl, $1 \mathrm{H}, 1 \mathrm{H}, 5 \mathrm{H}$-perfluoropentyl, $1 \mathrm{H}, 1 \mathrm{H}, 7 \mathrm{H}$-perfluoroheptyl and $1 \mathrm{H}, 1 \mathrm{H}, 9 \mathrm{H}-$ perfluorononyl fragments are shown below:
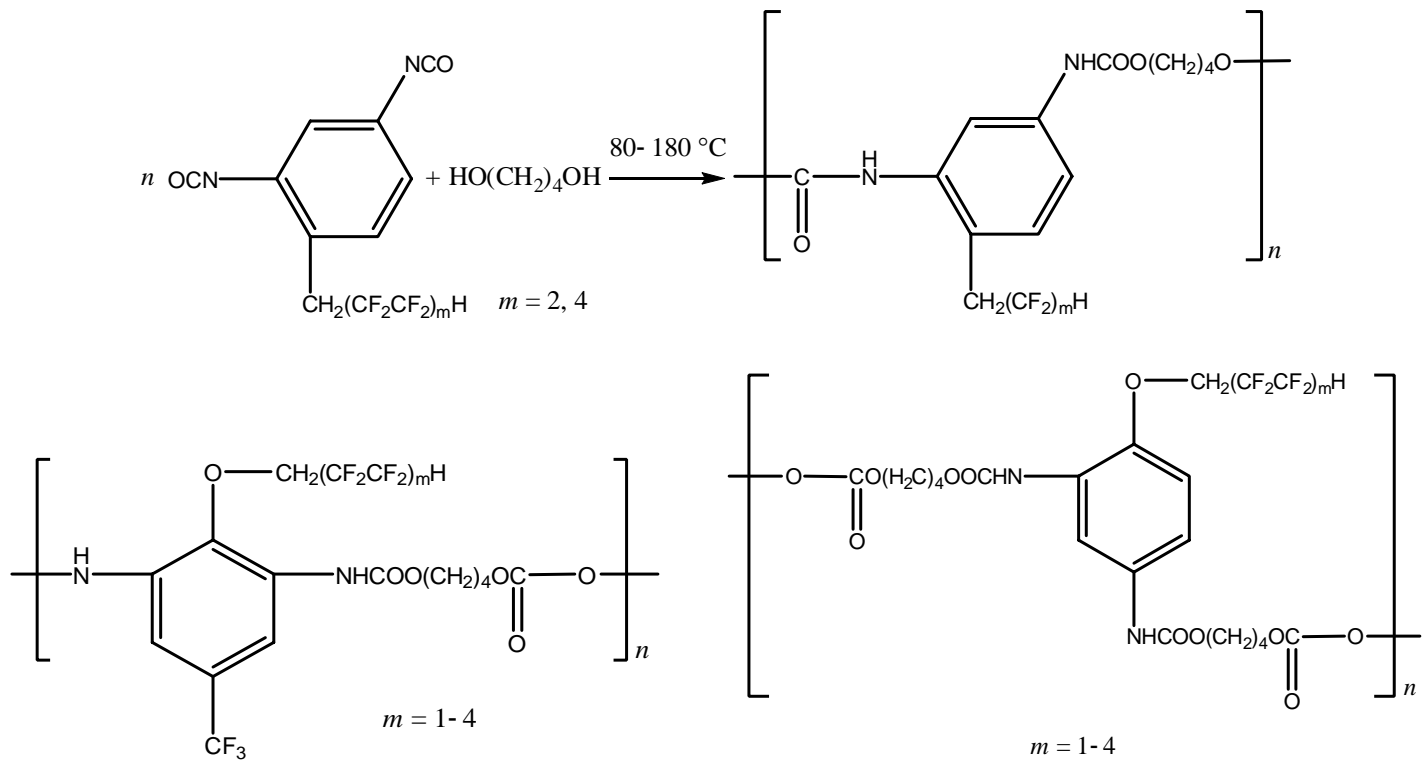

It is important to note that the introduction of fluorinated groups into polyurethanes not only gives them a good frost resistance [24], but also helps to change in surface properties of aromatic polyurethanes modified with tetrafluoropropanol [71]. The mechanical and adhesive properties of polyurethanes containing polyfluorinated diols are discussed in detail in [72-74].

Employees of N. D. Zelinskii Institute of Organic Chemistry RAS described the syntheses of fluorine-containing polyurethanes [75],<smiles>CCCPCOC(=O)NPNC(=O)OCC</smiles>

capable to operate under extreme conditions, with participation of chemical fluorinated hydroxylcontaining compounds with various chemical structures: 


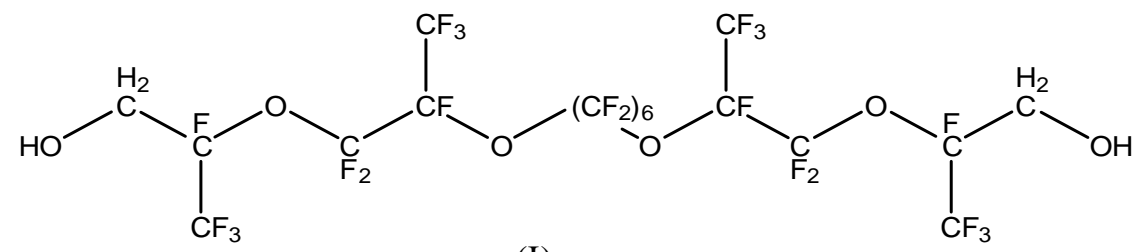

(I)<smiles>CC(C)(O)CCOC(C)(C)CO</smiles>

(II)<smiles>CC(C)(C)OCCC(C)(C)OCOC(F)(F)F</smiles>

(III)<smiles></smiles>

(IV)

Structure of obtained products was studied by IR- and ${ }^{1} \mathrm{H},{ }^{13} \mathrm{C}$ NMR- spectroscopy. The properties of obtained fluoropolymers are presented in Table 13.

Obtained fluorinated polyurethanes (via catalysis by di- $n$-butyldiyl dilaurate) based on polyfluorinated had a following structure [76],

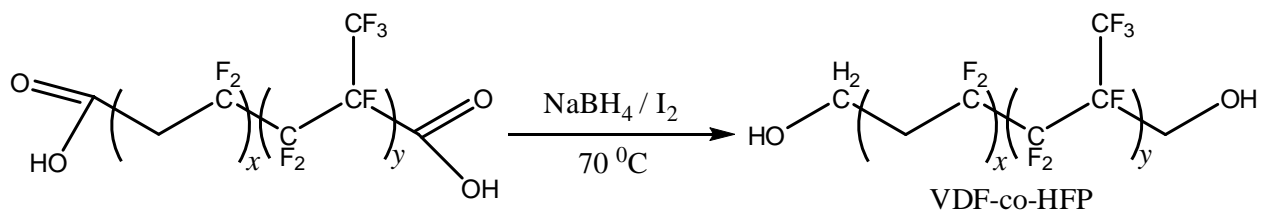

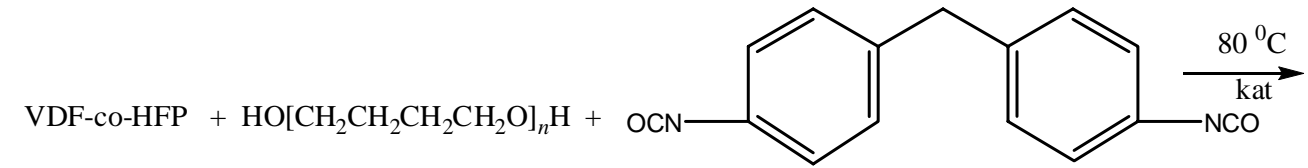<smiles>CCCONC(=O)Nc1ccc(Cc2ccc([N+](=O)[O-])cc2)cc1</smiles><smiles>Cc1ccc(Cc2ccc([N+](=O)OC(C)(C)COC(C)(C)C)cc2)cc1</smiles>

with onset temperature of intensive thermal decomposition at $304{ }^{\circ} \mathrm{C}$ and a tensile strength of 24.3 $\mathrm{MPa}$. The relative aggressive resistance of synthesized fluorinated polyurethanes is given in Table 
14.

The prospects of using fluorinated blocked isocyanates for producing fluoropolymer films with low surface energy (up to $10 \mathrm{mN} / \mathrm{m}$ ) were shown in [77-79]. In this case, a fluorine-containing blocked isocyanates had the following chemical structure:

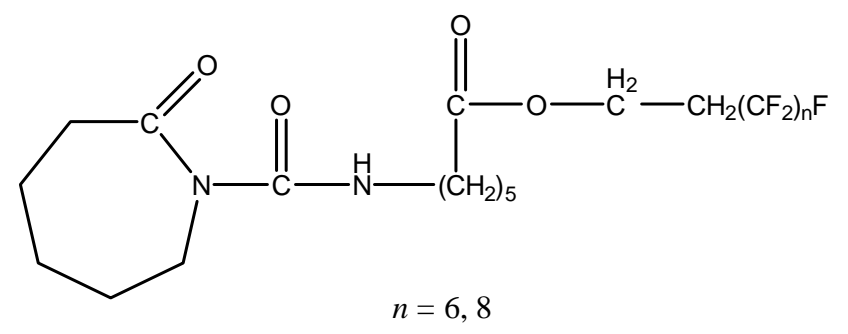

Table 13. Synthesis conditions and characteristics of resulting fluorinated aromatic polyurethanes.

\begin{tabular}{|c|c|c|}
\hline $\begin{array}{l}\text { Chemical } \\
\text { structure } \\
\text { of modifier }\end{array}$ & Reaction conditions & Product characteristic \\
\hline \multicolumn{3}{|c|}{ 2,4-toluene diisocyanate based polyurethanes } \\
\hline \multirow{2}{*}{ (I) } & $\begin{array}{c}60-150{ }^{\circ} \mathrm{C}, 17 \mathrm{~h}, \text { nitrogen, } \\
\mathrm{DMF}\end{array}$ & $\begin{array}{l}\text { Solid, elastic, light brown; limiting wetting angle } \\
\qquad 101^{\circ},[\eta]=0.006 \mathrm{dl} / \mathrm{g}(\mathrm{DMF})\end{array}$ \\
\hline & $\begin{array}{l}190{ }^{\circ} \mathrm{C}, 17 \mathrm{~h} \text {, nitrogen, } \\
\text { in the melt }\end{array}$ & $\begin{array}{l}\text { Solid, elastic, light brown; limiting wetting angle } \\
101^{\circ},[\eta]=0.01 \mathrm{dl} / \mathrm{g}(\mathrm{DMF}), \mathrm{T}_{5 \%}=261^{\circ} \mathrm{C}\end{array}$ \\
\hline \multicolumn{3}{|c|}{ 4,4'-diphenylmethane adiisocyanate based polyurethanes } \\
\hline (I) & $\begin{array}{l}190{ }^{\circ} \mathrm{C}, 15 \mathrm{~h} \text {, nitrogen, } \\
\text { in the melt }\end{array}$ & $\begin{array}{l}\text { Solid, orange tawny; limiting wetting angle } 110^{\circ} \text {, } \\
\qquad \mathrm{T}_{5 \%}=323^{\circ} \mathrm{C}\end{array}$ \\
\hline (II) + (III) & $\begin{array}{l}190{ }^{\circ} \mathrm{C}, 9 \mathrm{~h} \text {, nitrogen, } \\
\text { in the melt }\end{array}$ & $\begin{array}{c}\text { Colorless, transparent, limiting wetting angle } 113 \\
{ }^{\circ},[\eta]=0.13 \mathrm{dl} / \mathrm{g}_{\left(\mathrm{C}_{6} \mathrm{~F}_{6}\right), \mathrm{T}_{5} \%}=247^{\circ} \mathrm{C}, \mathrm{T}_{\text {glass. }}=- \\
143.6{ }^{\circ} \mathrm{C}\end{array}$ \\
\hline (IV) & $\begin{array}{l}\text { Room temperature, } \\
\text { stirring, nitrogen, DMF }\end{array}$ & $\begin{array}{l}\text { Brittle, yellowish; limiting wetting angle } 111^{\circ} \text {, } \\
\qquad \mathrm{T}_{5 \%}=247^{\circ} \mathrm{C}\end{array}$ \\
\hline
\end{tabular}

Table 14. Change in the weight of fluorinated polyurethane in various media (depending on concentration of modifier prepolymer introduced at the stage of production).

\begin{tabular}{|c|c|c|c|c|c|}
\hline \multirow{2}{*}{ Indicator } & \multicolumn{5}{|c|}{ Polyfluorinated alcohol content, \% wt. } \\
\cline { 2 - 6 } & 0 & 6 & 12 & 18 & 24 \\
\hline Weight change, $\%$, water, $90^{\circ} \mathrm{C}, 48 \mathrm{~h}$ & 2,42 & 2,19 & 1,94 & 1,91 & 1,88 \\
\hline Weight change, $\%$, water, $25^{\circ} \mathrm{C}, 22$ days & 2,50 & 2,13 & 1,95 & 1,81 & 1,79 \\
\hline Weight change, $\%$, jet aviation oil, $25^{\circ} \mathrm{C}, 22$ days & 1,59 & 1,32 & 1,20 & 1,03 & 0,76 \\
\hline
\end{tabular}


Weight change, $\%$, jet aviation oil, $90{ }^{\circ} \mathrm{C}, 48 \mathrm{~h}$

1,69

1,51

1,40

1,32

1,02

The fluorine content in the films obtained on basis of a liquid oligoester with hydroxyl groups, blocked polyisocyanate and fluorine-containing blocked isocyanate was $4 \% \mathrm{wt}$.

Introduction of fluorinated derivatives of diphenylolmethane at the stage of production of polydienurethane elastomers promotes the production of polymeric materials with increased hardness, tensile strength and wear resistance (see Table 15) [80].

Table 15. Melting points of fluorinated derivatives of diphenylolmethane.

\begin{tabular}{|l|l|l|} 
Melting point, ${ }^{\circ} \mathrm{C}$ \\
\hline
\end{tabular}

Analysis of molar mass values $\left(\mathrm{M}_{\mathrm{c}}\right)$ for chain segment enclosed between the nodes shows a sufficiently high degree of cross-linking is achieved via isocyanate curing of oligoisoprenes in the 
presence of PDFM (see Table 16).

Fluorinated polyurethanes are characterized by a shift in onset temperature of destruction by $15-100^{\circ} \mathrm{C}$ into high temperature range (as compared with initial polymer). Depending on structure of fluorine-containing modifier the samples weight loss $50 \%$ is later recorded at $70-85{ }^{\circ} \mathrm{C}$. Maximum effect is characteristic for polyurethanes modified by PDFM-4.

Table 16. Parameters of polyurethane spatial grid based on oligodienediol PDI- $1 K$ (polymer samples, equitable swollen in toluene).

\begin{tabular}{|c|c|c|c|c|}
\hline Modifier & $\begin{array}{c}\text { Fraction of } \\
\text { extracted } \\
\text { phase }\end{array}$ & $\begin{array}{c}\text { Equitable degree of } \\
\text { swelling }\end{array}$ & $\begin{array}{c}\text { Volume fraction of oligomer in } \\
\text { the swollen sample }\end{array}$ & $\begin{array}{c}\mathrm{M}_{\mathrm{c}}, \\
\mathrm{g} / \mathrm{mol}\end{array}$ \\
\hline PDFM-1 & 0,048 & 6,297 & 0,137 & 2225 \\
\hline PDFM-2 & 0,071 & 8,214 & 0,109 & 3332 \\
\hline PDFM-3 & 0,033 & 5,783 & 0,147 & 1959 \\
\hline PDFM-4 & 0,029 & 4,664 & 0,177 & 1430 \\
\hline
\end{tabular}

Curing of polyurethane elastomers in the presence of fraction $0.3 \mathrm{wt}$ (per 100 weight fraction of rubber PDI-1K) of fluorine-containing surfactants, where (see below) I - product of interaction of epichlorohydrin with $1 \mathrm{H}, 1 \mathrm{H}$-dihydroperfluoroheptane-1-ol, II - product of interaction of epichlorohydrin with $1 \mathrm{H}, 1 \mathrm{H}, 7 \mathrm{H}$-trihydroperfluoroheptane-1-ol, III - oligomeric product of interaction of propylene oxide with $1 \mathrm{H}, 1 \mathrm{H}, 11 \mathrm{H}$-trihydroperfluorundecan-1-ol, IV - product of esterification of stearic acid and 1H,1H,11H-trihydroperfluoroundecan-1-ol),
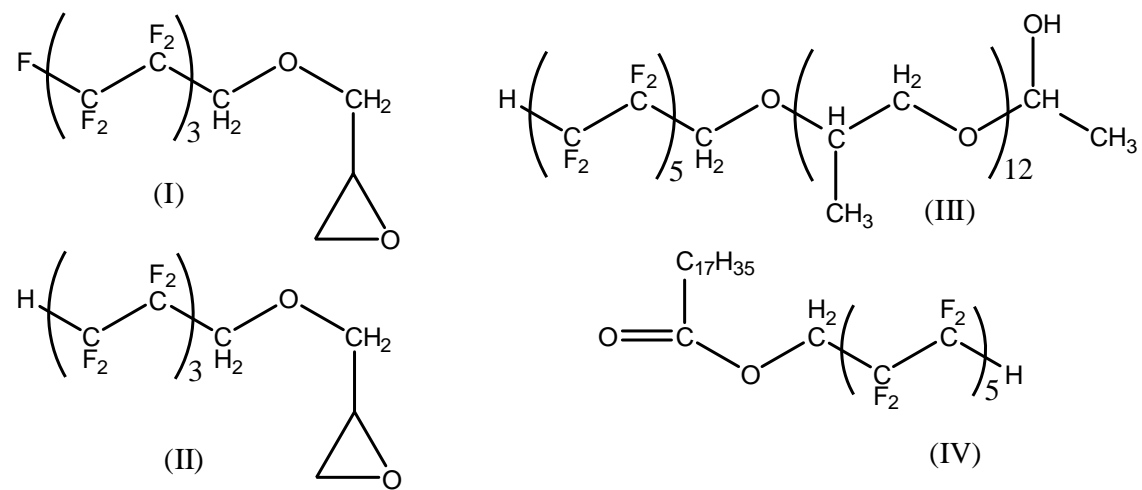

(IV)

that provided an increase in sedimentation stability of filled by chalk, marshalite, diatomite, wood flour oligomeric compositions, a decrease of microdefects in structure of cured material and hydrophobization of polyurethane surface (limiting wetting angle changed from $61^{\circ}$ to $105^{\circ}$ ) [81].

Modification of elastic polyurethanes by products of interaction of glycidol and $1 \mathrm{H}, 1 \mathrm{H}, 7 \mathrm{H}-$ 
trihydroperfluoroheptan-1-ol (see Structures I and II) provides increase in strength characteristics, thermal and hydrolytic stability, due to increase in crosslinking density (see Table 17) [82].<smiles>CC(C)CC(C)(C)OCC(O)CO</smiles>

Table 17. Properties of polyurethanes filled with layered silicate (talc)*.

\begin{tabular}{|c|c|c|c|c|}
\hline Modifier & $\begin{array}{c}\text { Nominal tensile strength, } \\
\mathrm{MPa}\end{array}$ & Elongation, $\%$ & $\begin{array}{c}\text { Peel strength, } \\
\mathrm{kN} / \mathrm{m}\end{array}$ & $\begin{array}{c}\text { Shore hardness A, } \\
\text { arbitrary unit }\end{array}$ \\
\hline- & 1,4 & 110 & 2,0 & 58 \\
\hline$(\mathrm{I})^{* *}$ & 1,8 & 100 & 3,5 & 61 \\
\hline$(\mathrm{II})^{* * *}$ & 2,1 & 100 & 3,1 & 62 \\
\hline
\end{tabular}

Content: * filler - 30 weight part; ** (I) 0.7 weight part; ** (II) 1.2 weight part

Polyfunctional products of N-polyfluoroalkylation of glycerol mono-e-aminocaproate, mono- and dipolyfluoroalkyl esters of phthalic acid, as well as glycidol and polyfluorinated alcohol esters described above, help to hydrophobization of polydienurethane and polythiourethane elastomers, leading to increase in elastomeric strength [83-87]
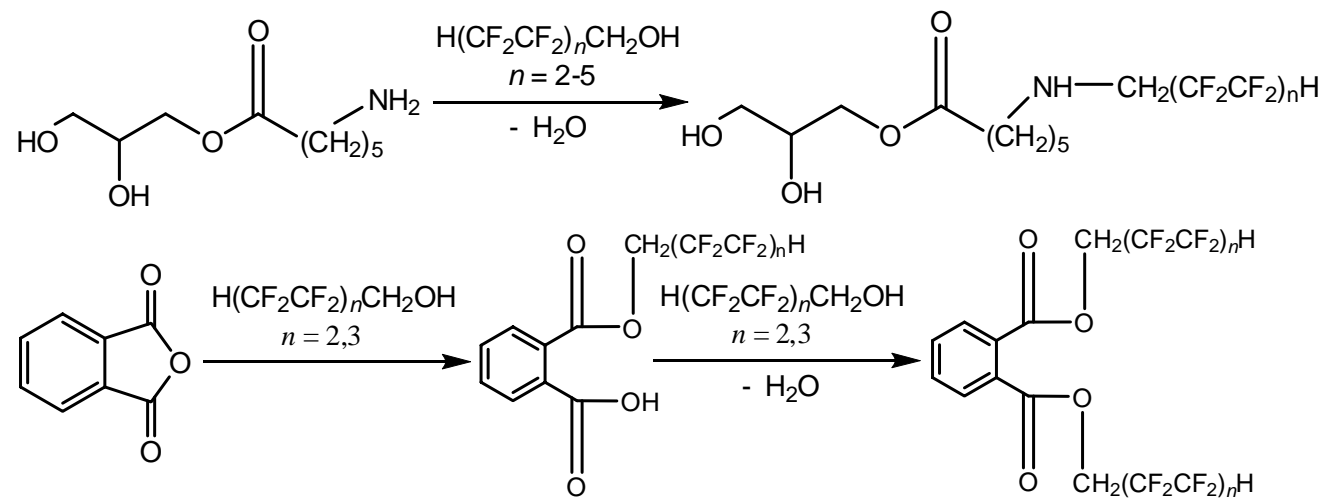

\section{Introduction of poly- and perfluorinated compounds into macromolecular systems at the stage of processing aliphatic polyamides, aromatic polyesters and polyurethanes. Surface modification of polymeric materials by poly- and perfluorinated compounds}

Modification of hetero-chain polymers at the stage of their processing (including surface treatment) by introduction of poly- and perfluorinated compounds is used to impart anti-adhesive (oil-, water-, and dirt-repellent) properties to materials and increase their tribotechnical 
characteristics. For these purposes, polymeric, oligomeric, and individual compounds with various chemical structures can be used - polytetrafluoroethylene, tetrafluoroethylene telomers, fluorinated alcohols and carboxylic acids, fluoroalkyl acrylates, fluorinated alkanes and ethers, etc. [88-117].

For surface treatment of finished polymer products (filaments, films, monolithic samples) can be applied the methods of direct gas-phase fluorination, sulfur tetra- and pentafluoride, nitrogen fluoride compounds $\left(\mathrm{NF}_{4}^{+} \mathrm{BF}_{4}^{-}, \mathrm{NF}_{4}^{+} \mathrm{AsF}_{6}^{-}\right)$and phosphorus $\left.\left.\left(\mathrm{C}_{4} \mathrm{H}_{9}\right)_{4} \mathrm{PF} \cdot 2 \mathrm{HF}\right) \cdot 2 \mathrm{HF}\right)$, halogen fluorides $\left(\mathrm{ClF}_{3}, \mathrm{ClF}, \mathrm{BrF}_{3}, \mathrm{IF}_{5}\right)$, fluorides of metals and nonmetals $\left(\mathrm{SbF}_{3}, \mathrm{SbF}_{3} \mathrm{Cl}_{2}, \mathrm{SeF}_{4}\right)$, xenon fluorides $\left(\mathrm{XeF}_{2}, \mathrm{XeF}+\mathrm{SbF}_{6^{-}}, \mathrm{XeF}+\mathrm{Sb}_{2} \mathrm{~F}_{11}{ }^{-}\right), \mathrm{NF}$ reagents, fluorinated N-fluoropyridines, $\mathrm{N}$ fluorosulfonimides, dialkylaminosulfotrifluorides DAST, MethylDAST, Morpho-DAST and Deoxo-Fluor), fluorinating systems $\left(\mathrm{SF}_{4}+\mathrm{BF}_{3}, \mathrm{SF}_{4}+\mathrm{TiF}_{4}, \mathrm{HF}+\mathrm{SF}_{4}\right)$, OF-reagents $\left(\mathrm{CF}_{2}(\mathrm{OF})_{2}\right.$, $\left.\mathrm{CF}_{3} \mathrm{C}(\mathrm{O}) \mathrm{OF}\right)$, complex tetrafluorocobaltates, plasma treatment, and radiation exposure in the presence of fluorinated compounds [2-16, 59, 89-92]. Fluorinated surfactants (epilamas "Polizam", "Films") are widely used as glazing agents.

Obtained fluorine-containing polymers and composite materials are used as:

a) filters for aggressive liquids, nets and other woven structures for filtering aggressive liquid and gaseous media, filter-splash boards for trapping acid splashes, oxidizing agents in process of manufacturing of sulfuric and phosphoric acids, fertilizers;

b) reinforced membranes for diaphragm electrolysis of sodium chloride in the process of manufacturing of sodium hydroxide and chlorine;

c) protective equipment, special clothing, materials and products with reduced combustibility for use in environments with high oxygen content and also - for protection against molten metals;;

d) biologically stable and bioinert medical devices (prostheses of internal organs, suture materials, devices for filtering biological media);

e) heat-resistant non-combustible insulating materials in cables and various electrical and radio devices;

f) highly loaded antifriction materials and friction units;

g) resistant seals and stuffing box packing, capable to operating in extreme conditions.

Modification of polymer fabrics, films, coatings (at processing stage and surface modification) by low- and high-molecular weight polytetrafluoroethylene (Forum, Cherflon, Nuva TTH) helps to production of ultra-materials (with limiting wetting angle more than $120^{\circ}$ ) and also super-hydrophobic materials (with limiting wetting angle over $150^{\circ}$ ) [1, 90, 91, 109-111].

In [109-111] studied the structure and properties of coatings formed at the surface of polyethylene terephthalate materials from solutions of ultrafine polytetrafluoroethylene in 
supercritical carbon dioxide and tetrafluoroethylene telomers in acetone. It was shown that a polytetrafluoroethylene film is formed at the surface of fibers, which reduces the surface energy of polyester material, ensuring its ultrahydrophobicity, high air- and vapor-permeability, low water absorption, and washing fastness (see Tables 18-21) [90, 91, 109]

Table 18. X-ray diffraction analysis of modified PET fabrics.

\begin{tabular}{|c|c|c|}
\hline \multirow{2}{*}{ Treating conditions for fabrics } & \multicolumn{2}{|c|}{$\begin{array}{c}\text { Diffraction intensity } \mathrm{I}^{\mathrm{n}} \text { oбp }(2 \theta), \\
\text { pulse/s }\end{array}$} \\
\cline { 2 - 3 } Untreated & $2 \theta=13^{\circ}$ & $2 \theta=25,5^{\circ}$ \\
\hline $\begin{array}{c}\text { Treated in supercritical } \mathrm{CO}_{2} \text { at pressure of } 20 \mathrm{MPa} \\
\text { temperature of } 90^{\circ} \mathrm{C} \text { for } 120 \mathrm{~min}\end{array}$ & 536,1 & 2390,4 \\
\hline $\begin{array}{c}\text { Treated by solution Forum in supercritical } \mathrm{CO}_{2} \text { at pressure of } \\
20 \mathrm{MPa} \text {, temperature of } 90^{\circ} \mathrm{C} \text { for } 120 \text { min }\end{array}$ & 522,4 & 2378,3 \\
\hline Coefficient of variation, $\%$ & \multicolumn{2}{|c|}{2,0} \\
\hline
\end{tabular}

Table 19. Indicators of hydrophobicity of PET fabrics treated by solution "Forum" in supercritical $\mathrm{CO}_{2}$ at various pressures and temperatures.

\begin{tabular}{|c|c|c|c|c|c|c|}
\hline \multicolumn{2}{|c|}{ Treatment conditions } & \multirow{2}{*}{$\begin{array}{c}\text { Content of } \\
\text { "Forum" on } \\
\text { the surface, } \\
\mathrm{g} / \mathrm{m}^{3}\end{array}$} & \multicolumn{2}{|c|}{$\begin{array}{l}\text { Limiting wetting } \\
\text { angle, }{ }^{\circ}\end{array}$} & \multicolumn{2}{|c|}{$\begin{array}{l}\text { Duration of drop of water } \\
\text { absorption, min }\end{array}$} \\
\hline $\begin{array}{l}\text { Pressure, } \\
\mathrm{MPa}\end{array}$ & $\begin{array}{l}\text { Temperature, } \\
{ }^{\circ} \mathrm{C}\end{array}$ & & $\begin{array}{l}\text { Before } \\
\text { abrasion }\end{array}$ & $\begin{array}{c}\text { After } \\
\text { abrasion }\end{array}$ & $\begin{array}{l}\text { Before } \\
\text { abrasion }\end{array}$ & $\begin{array}{c}\text { After } \\
\text { abrasion }\end{array}$ \\
\hline 20 & 90 & 0,752 & 137 & 133 & More than 50 & More than 50 \\
\hline 40 & 70 & 0,498 & 139 & 132 & More than 50 & More than 50 \\
\hline 50 & 70 & 0,925 & 138 & 136 & More than 50 & More than 50 \\
\hline 50 & 90 & 0,856 & 135 & 127 & More than 50 & More than 50 \\
\hline
\end{tabular}

Table 20. Relative stability of hydrophobicity effect to operational impacts.

\begin{tabular}{|c|c|c|c|c|}
\hline \multirow{2}{*}{ Agent } & \multicolumn{4}{|c|}{ Limiting wetting angle, } \\
\cline { 2 - 5 } & Original polyester fabrics & After abrasion & $\begin{array}{c}\text { After } \\
\text { washing }\end{array}$ & $\begin{array}{c}\text { After dry } \\
\text { cleaning }\end{array}$ \\
\hline Cherflon & $130 \pm 3$ & $135 \pm 3$ & $134 \pm 3$ & $130 \pm 3$ \\
\hline Nuva TTH & $132 \pm 4$ & $117 \pm 4$ & $108 \pm 5$ & $126 \pm 5$ \\
\hline
\end{tabular}

Table 21. Hydrophobicity characteristic of polyester film three times treated by tetrafluoroethylene telomere solution. 


\begin{tabular}{|c|c|}
\hline Type of treatment & Limiting wetting angle, $^{\circ}$ \\
\hline Untreated & $72 \pm 3$ \\
\hline Treated by telomere, thermofixation & $92 \pm 3$ \\
\hline Treated by telomere, abrasion & $88 \pm 2$ \\
\hline
\end{tabular}

In [112-114], the practical usefulness of fluoroalkyl acrylates as hydrophobisators of fiberforming polymers for targeted production of textile materials with antistick properties was noted. In domestic practice, the initiator of scientific area related to the study of chemical addition of organofluorine compounds to chemical fibers was Z. A. Rogovin [44].

Grafted fluoropolymers, due to their ability to form a uniform polymer layer on the polymer surface, have proven to be effective modifiers for polyester films, filaments and fibers. Upon receipt of fluorine-containing grafted polymers, the main factor determining the level of properties (release, dielectric, protective) is the chemical structure of fluoroalkyl radical.

It was established in [113] that the release properties begin to manifest when there are at least four perfluorinated carbon atoms in the radical with $\mathrm{F}_{3} \mathrm{C}$ group at the end of chain, and increase significantly when this chain is elongated. The optimal amount of grafted polymer is at least $2 \%$ (increase in oil and water repellent properties while maintaining strength characteristics). The process of grafted polymerization of fluorine-containing unsaturated monomers to PET can be organized according to periodic, semi-continuous and continuous schemes.

At present, fluorinated alkyl acrylates with various chemical structures are produced in Russian and world-wide industry [88, 89, 112-114]:<smiles>C=CC(=O)OCCC</smiles> 


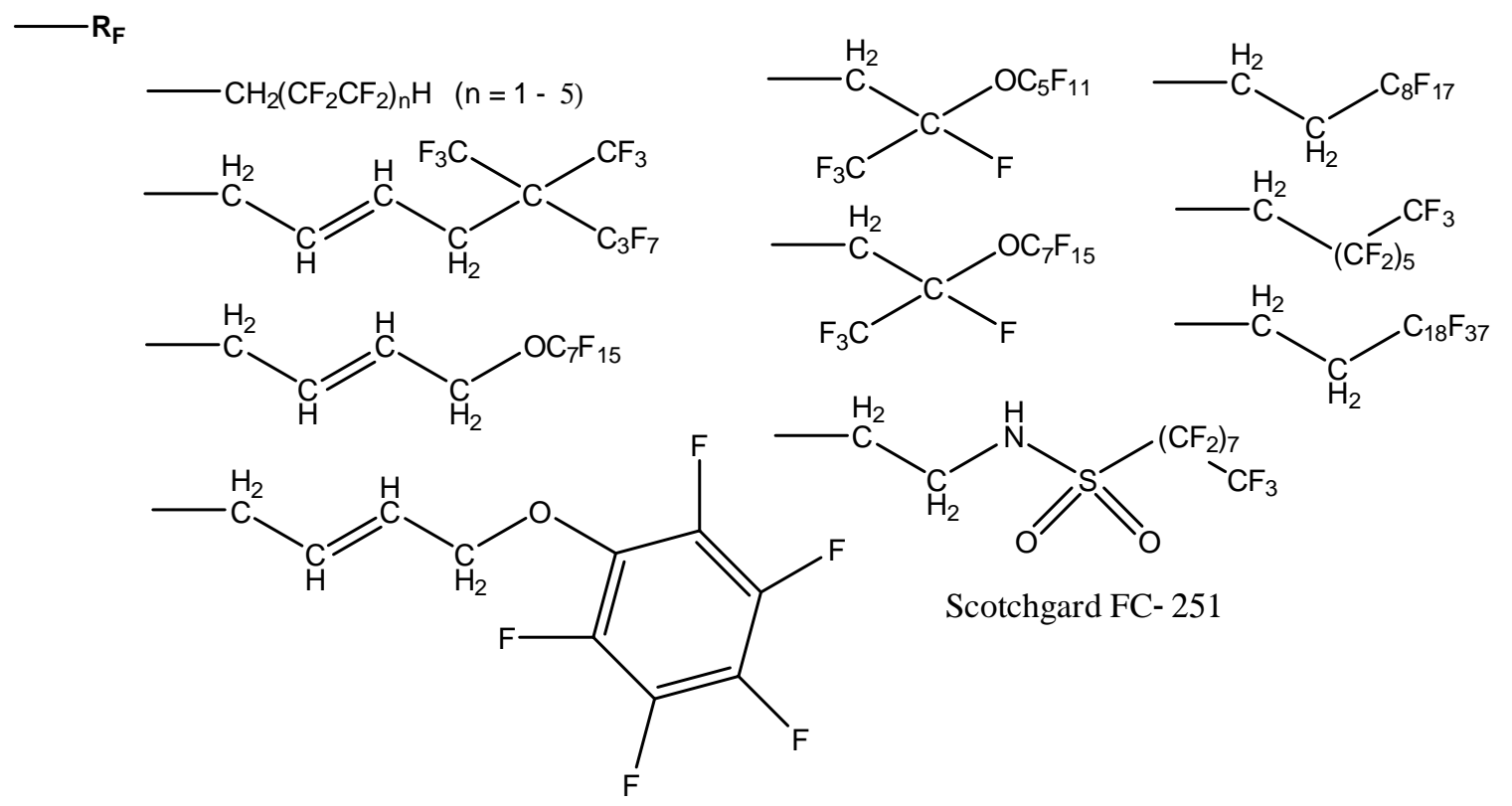

For grafting, fluoromonomers with unsaturated substituent in ester fragment can be used [44]:<smiles>C=COC(=O)CC(F)(F)F</smiles><smiles>C=COC(=O)C(C(F)(F)F)C(F)(F)F</smiles>

A characteristic feature of esters of fluorinated carboxylic acids, which impedes the possibility of their practical application, is ability to easily hydrolyze due to the high electrophilicity of carbonyl carbon, which arises due to electron-accepting effect of fluorine atoms. It is important that grafted polymers with normal structure of fluoroalkyl chain are characterized by a higher level of release properties than with a branched structure.

A surface modification of polyester and polyamide fibers by grafting of fluoromonomers is carried out using traditional redox systems: $\mathrm{Fe}^{2+}-\mathrm{H}_{2} \mathrm{O}_{2}$ or $\mathrm{Cu}^{2+}-\mathrm{H}_{2} \mathrm{O}_{2}$. To increase the degree of conversion of fluorinated monomer to grafted polymer, reversible redox systems (for example, $\mathrm{Fe}^{2+}$ $-\mathrm{H}_{2} \mathrm{O}_{2}$ - ascorbic acid (or hydrazine)) can be successfully used.

It is known to use radiation grafting polymerization for synthesis and modification of track membranes (for nuclear filters) and gas separation polyester membranes. To obtain grafted PET copolymers, a block polymerization method at $80^{\circ} \mathrm{C}$ in the presence of benzoyl peroxide can be used. In this case the yield of grafted fluoropolymer is 96-98\% [112].

One of areas of fluoropolymer chemistry is synthesis of flip-flop oleophobic-hydrophilic fluorine-containing PET copolymers. Such grafted systems are capable of reorienting PET filaments at these surface during transition from air to water (during washing). The use of fluorine-containing 
monomers containing an oxirane ring allows to carry-out the polymer-like transformations in grafted macromolecular chains to be made possible to impart a number of valuable properties to polyester materials. The use of fluorine-containing surfactants as modifiers of polymer fibers is described in detail in [94].

Modification of polycaproamide by poly- and perfluorinated compounds was systematized in [115]. Introduction of $1 \%$ fluoroalkyl acrylates into polyamide makes it possible to obtain by pressing the polymer films with water-repellent properties, and under plasma treatment, the acrylates are grafted onto polycaproamide, increasing its fire resistance.

The radical grafting of $1 \mathrm{H}, 1 \mathrm{H}, 5 \mathrm{H}$-trihydroperfluoropentyl acrylate to polycaproamide yarn in the presence of tert-butyl hydroperoxide helps to production of fluoropolymer with a fluorine content of $0.87-1.33 \%$ [115-117]. It was found that detachment of hydrogen atom from fragment $\mathrm{HN}-\left(\mathrm{CH}_{2}\right)_{5}-\mathrm{C}(=\mathrm{O})-$ goes into $\alpha$-position to the NH-group:

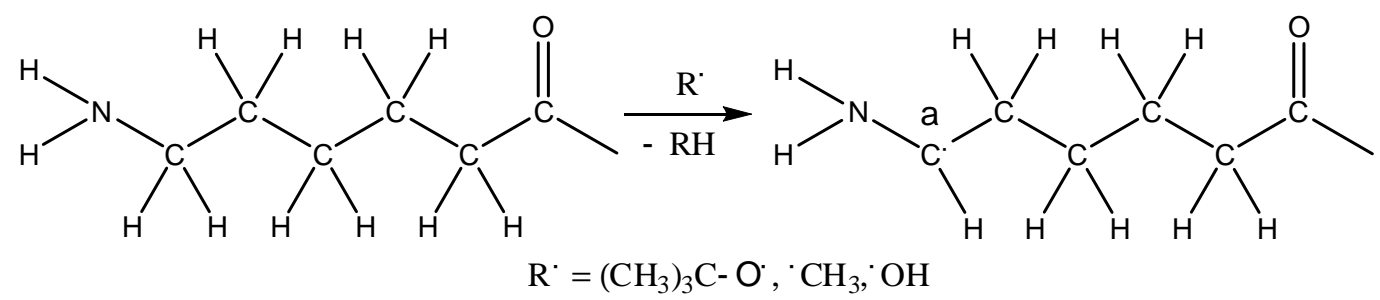

The resulting macroradical then reacts with $1 \mathrm{H}, 1 \mathrm{H}, 5 \mathrm{H}$-trihydroperfluoropentyl acrylate, which is facilitated by electrophilic nature of terminal $\mathrm{CH}_{2}$ group:

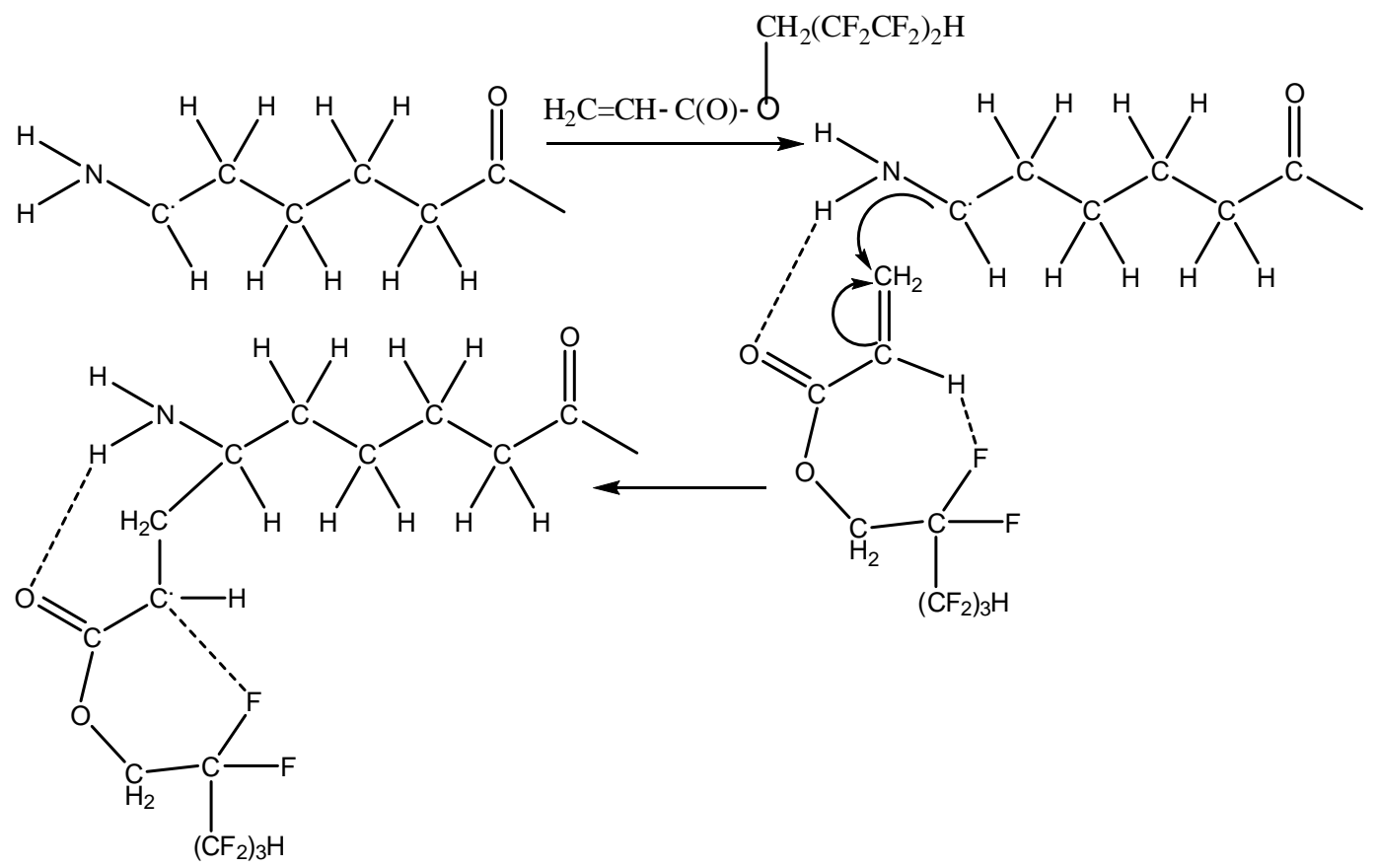

The ester group (and the terminal NH-group associated with ester group) are involved in 
stabilizing of radicals structure, which ultimately leads to the following copolymer:

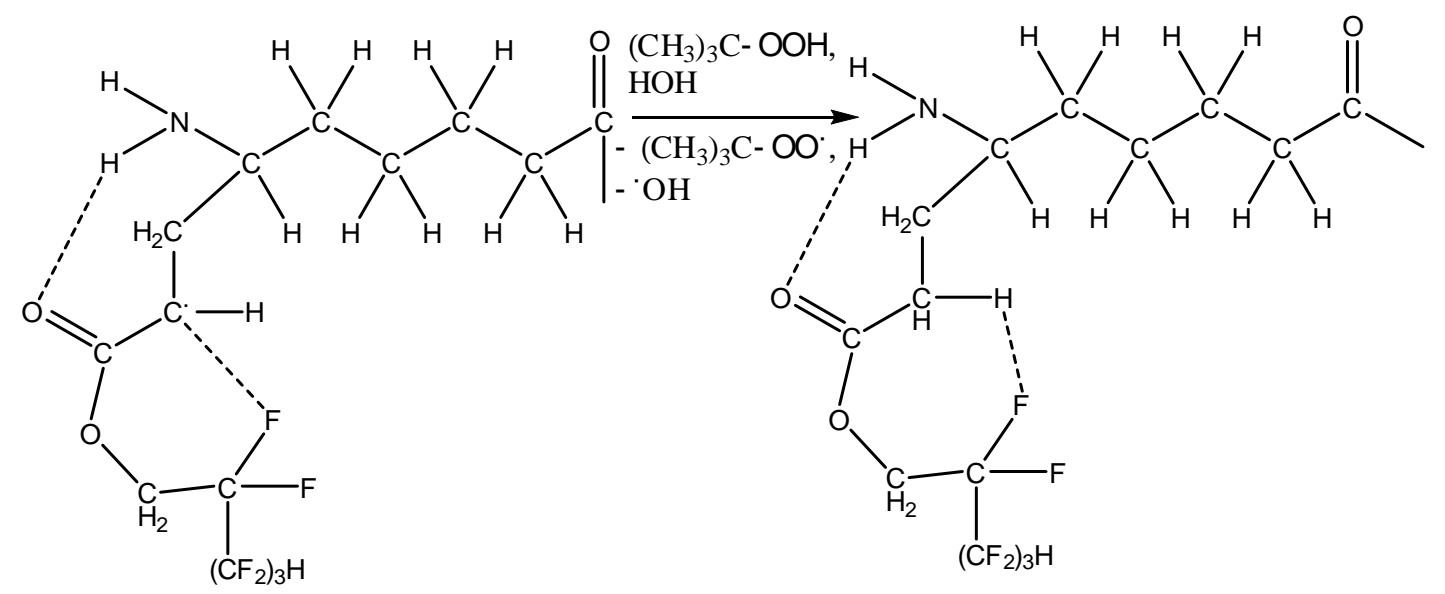

The characteristic property of grafting $1 \mathrm{H}, 1 \mathrm{H}, 5 \mathrm{H}$-trihydroperfluoropentyl acrylate to the polycaproamide fiber is that in grafting conditions no significant amount of homopolymer is formed, and resulting copolymer is characterized by enhanced physical and mechanical properties due to a possible increase in degree of molecular orientation in amorphous phase of polymer caused by formation of cyclic associates (see Table 22) [117].

Table 22. Change in physico-mechanical properties of original polycaproamide yarn and yarn treated by polyfluorinated acrylate

\begin{tabular}{|c|c|c|}
\hline Grafting time, $\mathrm{h}$ & Breaking load, $\mathrm{N}$ & Elongation at break, $\%$ \\
\hline 0 & 9,1 & 14,4 \\
\hline 1 & 9,4 & 16,5 \\
\hline 2 & 9,3 & 15,6 \\
\hline 3 & 9,3 & 14,0 \\
\hline 4 & 9,7 & 21,8 \\
\hline
\end{tabular}

Polyfluoroalkylation of oligo- and polycaproamides by polyfluorinated alcohols and chlorosulphites based on them $\mathrm{H}\left(\mathrm{CF}_{2} \mathrm{CF}_{2}\right)_{n} \mathrm{CH}_{2} \mathrm{OS}(\mathrm{O}) \mathrm{Cl}$ is described in $[67,115]$. The use of polyfluoroalkylchlorosulfites allows to introduction of poly- and perfluorinated fragments into macromolecular systems containing hydroxyl and carboxyl groups [118-127].

The reaction of $1 \mathrm{H}, 1 \mathrm{H}, 5 \mathrm{H}$-trihydroperfluoropentylchlorosulfite (the product of the interaction of polyfluorinated alcohol and thionyl chloride in the presence of acid amides [128131]) with $\varepsilon$-aminocaproic acid oligomers $(n=60-80)$ in the presence of triethylamine was carried out for 2 hours at $60-65^{\circ} \mathrm{C}$, with fluorine content $1.09-1.56 \%$, yield $75.6 \%$ ): 


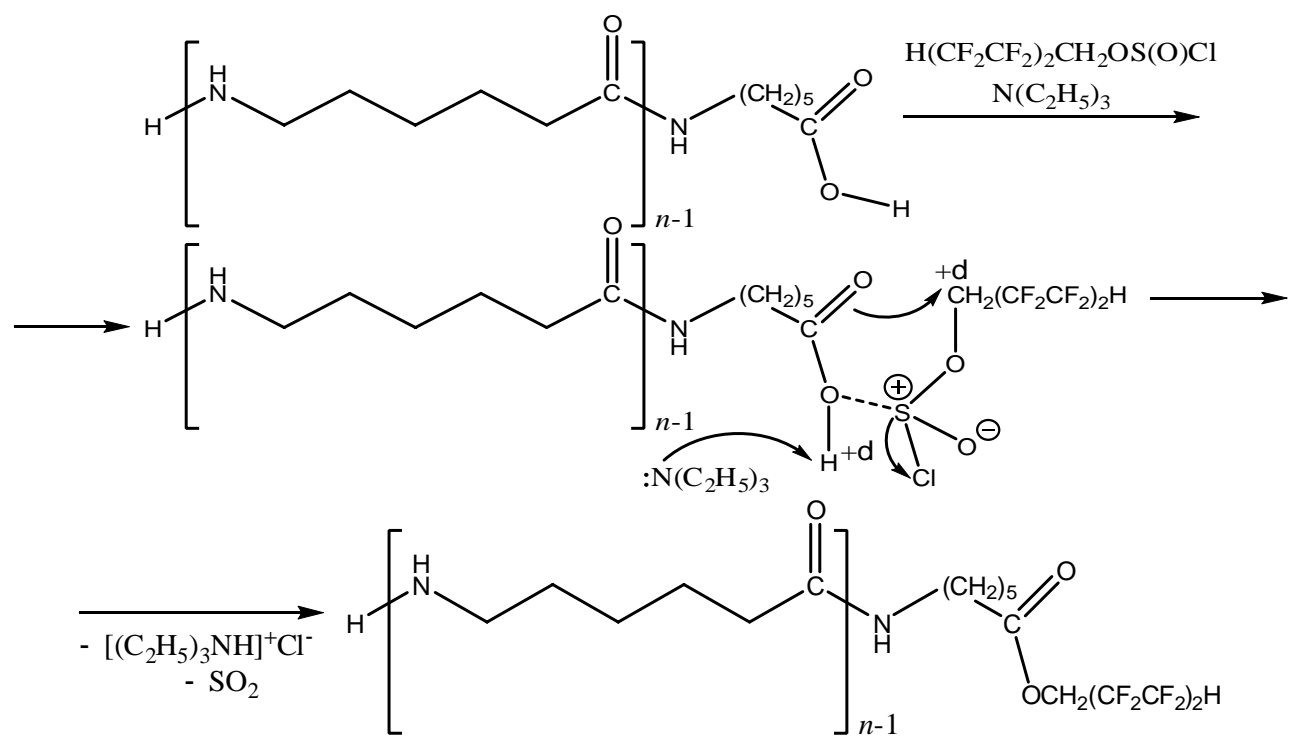

The product $N, O$-polyfluoroalkylation (with a yield of $15.6 \%$, m.p. $220-228^{\circ} \mathrm{C}$, and fluorine content $3.09 \%$ ), insoluble in boiling water was also found in mixture.

The mechanism of $\mathrm{N}$ - and O-polyfluoroalkylation of oligocaproamides with polyfluorinated alcohols differs from reaction mechanism of polyfluoroalkylchlorosulfites with oligomer [115, 132134]. The increased acidity of polyfluorinated alcohol and low electron density of oxygen atom in the hydroxyl group complicates the esterification of oligomer carbonyl group, and interaction can go with breaking of amide bond, and the presence of electrophilic center on carbon atom of $\mathrm{CH}_{2}$ group helps to attack of lone electron pair to nitrogen atom of terminal $\mathrm{NH}_{2}$ group of oligomer molecule in this center. The main product of reaction $1 \mathrm{H}, 1 \mathrm{H}, 5 \mathrm{H}$-trihydroperfluoropentan-1-ol with oligomer at $141{ }^{\circ} \mathrm{C}(12 \mathrm{~h})$ is the product of $\mathrm{N}$-polyfluoroalkylation (stabilization of transition structure is facilitated by formation of the intramolecular hydrogen bond $-\mathrm{F} \cdots \mathrm{H}-$ ):

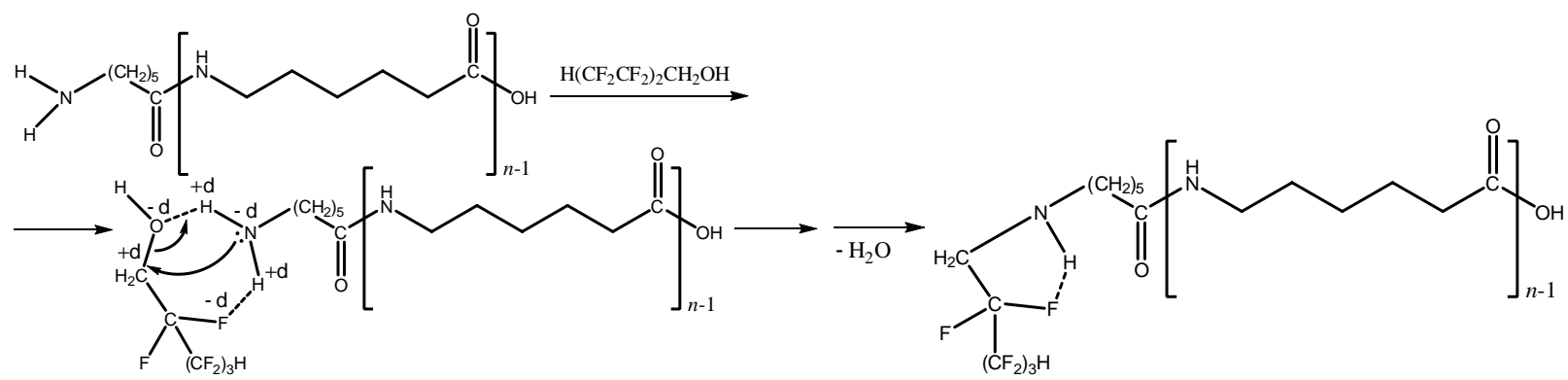

The use of $N$ - and $O$-polyfluoroalkylation products of butadiene-isoprene oligodiols and their esters with $\varepsilon$-aminocaproic acid oligomers 


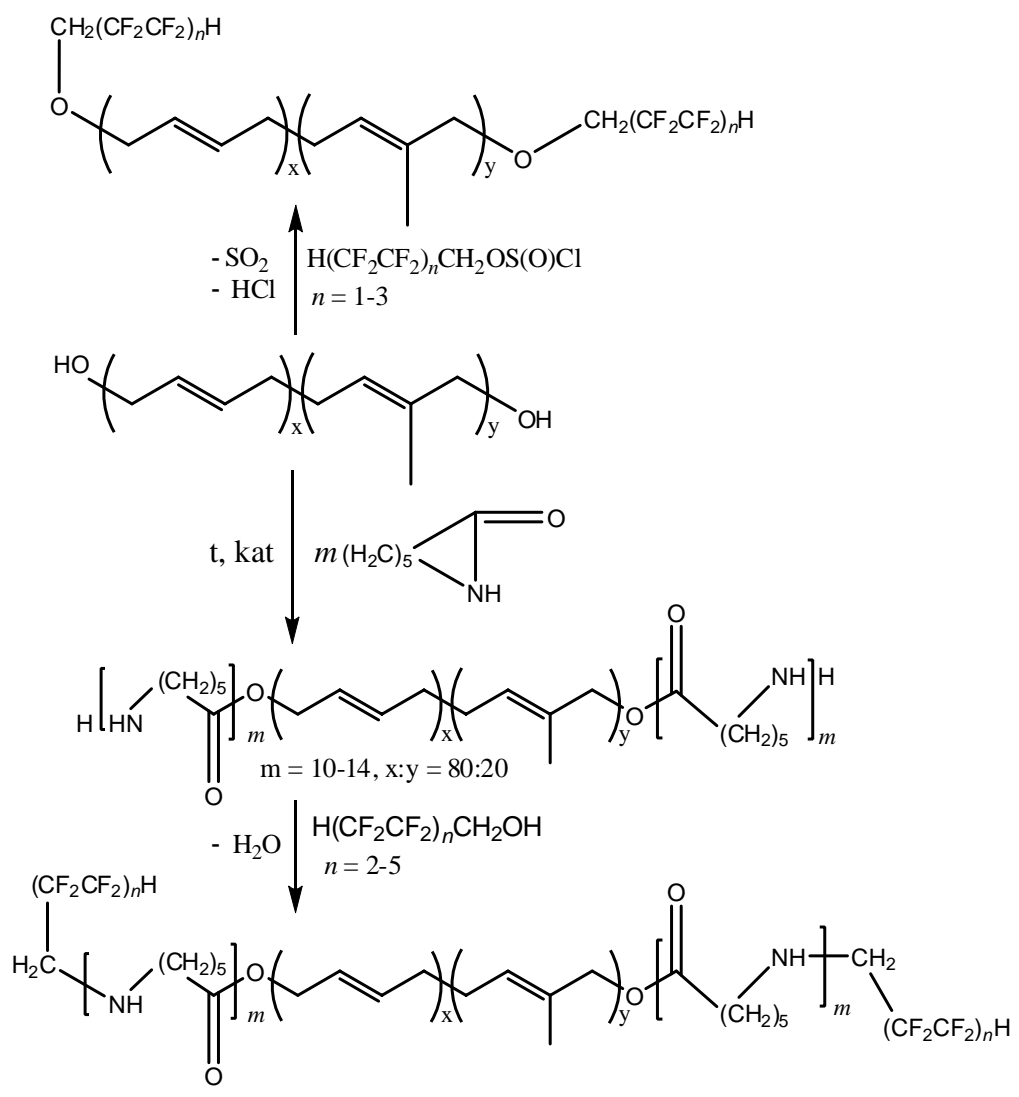

as a components of polyurethane compositions, imparts the latter increased moisture-, oil- and gas resistance $[135,136]$. In this case, the fluorinated oligomers are capable to exert a plasticizing effect. The presence of multiple bonds in the obtained compounds allows further chemical transformations associated with introduction of various functional groups (chlorine, peroxide fragments).

One of the ways for modification of polymers by poly- and perfluorinated compounds is creation of antifriction polymer materials. The use of fluorinated alkanes $\mathrm{C}_{n} \mathrm{~F}_{2 n+2}$ and $\mathrm{H}\left(\mathrm{CF}_{2}\right)_{n} \mathrm{Cl}$, fluorinated alcohols and esters of $\varepsilon$-aminocaproic acid as a polymer modifiers is expedient for production of textile and cord fabrics, suture surgical materials and compositions for prosthetics of human organs, as well as details of friction units [84, 137, 138].

The esters of polyfluorinated alcohols and $\varepsilon$-aminocaproic acid $\mathrm{H}_{2} \mathrm{~N}-\left(\mathrm{CH}_{2}\right)_{5}-\mathrm{C}(=\mathrm{O})-\mathrm{O}-$ $\mathrm{CH}_{2}\left(\mathrm{CF}_{2} \mathrm{CF}_{2}\right)_{n} \mathrm{H}(n=1,2)$ promote to decrease of temperature during polycaproamide processing and increase of melt flow [139]. Tribological tests revealed that introduction of $0.1 \%$ wt. most active $1 \mathrm{H}, 1 \mathrm{H}, 3 \mathrm{H}$-trihydroperfluoropropyl esters of $\varepsilon$-aminocaproic acid leads to a 3 -fold increase in wear resistance of polycaproamide.

Perfluorinated alkanes and polyfluorinated alcohols introduced at the polycaproamide processing stage (extrusion compounding, compression molding, press casting) promote to improvement of complex of composite material properties (see Table 23) [140]. 
Table 23. Receipt of fluorine-containing polyamide composition and its properties.

\begin{tabular}{|c|c|c|c|}
\hline $\begin{array}{c}\text { Fluorine-containing } \\
\text { modifier }\end{array}$ & $\begin{array}{c}\text { Contact temperature, }{ }^{\circ} \mathrm{C} / \\
\text { Friction coefficient }\end{array}$ & $\begin{array}{c}\text { Elastic } \\
\text { modulus, } \mathrm{GPa}\end{array}$ & $\begin{array}{c}\text { Charpy impact } \\
\text { strength, } \mathrm{kJ} / \mathrm{m}^{2}\end{array}$ \\
\hline$-{ }^{1}$ & $105 / 0,7-1,2$ & 7,8 & 27 \\
\hline $\mathrm{H}\left(\mathrm{CF}_{2} \mathrm{CF}_{2}\right)_{2} \mathrm{CH}_{2} \mathrm{OH}^{2}$ & $58 / 0,4$ & 10,2 & 23 \\
\hline $\mathrm{H}\left(\mathrm{CF}_{2} \mathrm{CF}_{2}\right)_{4} \mathrm{CH}_{2} \mathrm{OH}^{3}$ & $45 / 0,4$ & 11,2 & 24 \\
\hline Fluoroalkane & $95 / 0,5$ & 9,5 & 18 \\
\hline
\end{tabular}

The composition, \% wt:

${ }^{1}$ polycaproamide - 85 , carbon fiber - 15 ;

${ }^{2}$ polycaproamide - 52, carbon fiber - 30, high-pressure polyethylene - $12,1 \mathrm{H}, 1 \mathrm{H}, 5 \mathrm{H}-$

trihydroperfluoropentan-1-ol - 0.1, powdered carbon black - 6;

${ }^{3}$ polycaproamide - 45, carbon fiber - 40, high pressure polyethylene - $11,1 \mathrm{H}, 1 \mathrm{H}, 9 \mathrm{H}-$

trihydroperfluorononan-1-ol - 0.3, powdered carbon black - 4;

${ }^{4}$ polycaproamide - 70, carbon fiber - 30, fluoroalkane - 0.1 .

Structural studies of modified polycaproamide films formed from solutions of formic acid indicate that introduction of polyfluorinated alcohols increases the proportion of polymer molecules in planar trans-conformation and formation of extended hydrogen-bonded layers oriented perpendicular to the film plane [115].

Lowly boiling points of polyfluorinated alcohols $\mathrm{H}\left(\mathrm{CF}_{2} \mathrm{CF}_{2}\right)_{n} \mathrm{CH}_{2} \mathrm{OH}\left(760 \mathrm{mmHg}\right.$ : $109^{\circ} \mathrm{C}$ $n=1 ; 141{ }^{\circ} \mathrm{C} n=2 ; 170{ }^{\circ} \mathrm{C} n=3 ; 202{ }^{\circ} \mathrm{C} n=4 ; 230{ }^{\circ} \mathrm{C} n=5$ according to $\mathrm{TU}($ technical condition) 2421-151-05807960-2005), in comparison with the melt temperatures of polyamides, polyesters and polyurethanes, promote to possible volatilization of these modifying additives in the process of their combining with polymer melts. By polyfluorinated alcohols modification (in form of their solutions with given concentration) of polycaproamide granules at the stage of their drying at 100$115^{\circ} \mathrm{C}$ in a drum dryer, followed by vacuuming of solvent by melt technology, fibers and injection samples were formed and their properties were studied (see Table 24) [115].

Table 24. Change in physical and mechanical properties during storage of polycaproamide fibers modified by $3.5 \cdot 10^{-3} \% \mathrm{wt}$. $1 \mathrm{H}, 1 \mathrm{H}, 5 \mathrm{H}$-trihydroperfluoropentan-1-ol and $5 \cdot 10^{-2} \% \mathrm{wt}$. $\mathrm{N}, \mathrm{N}$-bis-

(2,2,6,6-tetramethyl-4-piperidinyl (the original fiber - in the numerator, modified fiber - in the denominator).

\begin{tabular}{|c|c|c|}
\hline Fiber & Breaking load, N & Elongation, $\%$ \\
\hline Initial & $16,0 / 14,6$ & $16,2 / 22,5$ \\
\hline After aging for 2 years & $8,5 / 12,9$ & $16,0 / 22,5$ \\
\hline
\end{tabular}


The stabilizing effect of small amounts of polyfluorinated alcohols is manifested in the reduction of undesirable tribo-oxidative processes, leading to the appearance of black products located in concentric circles in the direction of friction (see Figure 2).

In $[69,115]$ it was postulated that the strength of polyfluorinated alcohol in the polymer is so high that it remains in polyamide structure after granulation and fiber forming operations under processing conditions at $255^{\circ} \mathrm{C}$ and significant shear stress during extrusion and casting. However, further studies [138] do not exclude the diffusion of polyfluorinated alcohol molecules onto product surface in case increasing temperature during triboprocess of samples and formation of a boundary self-lubricating layer.

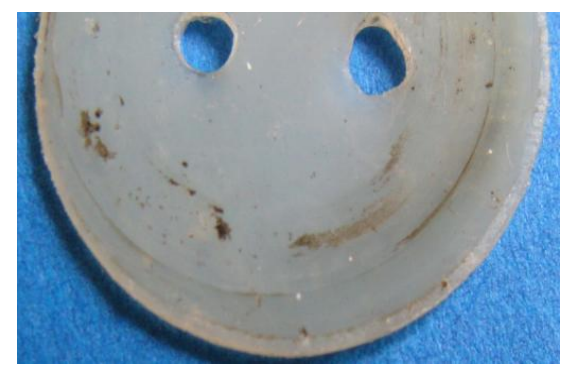

a

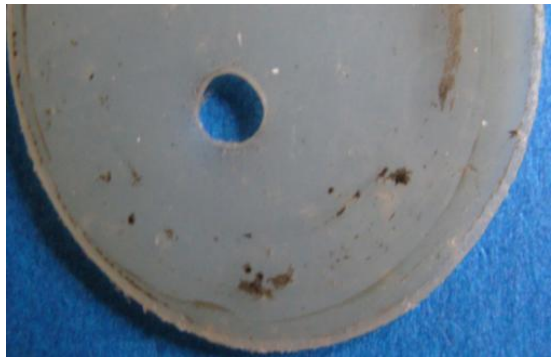

b

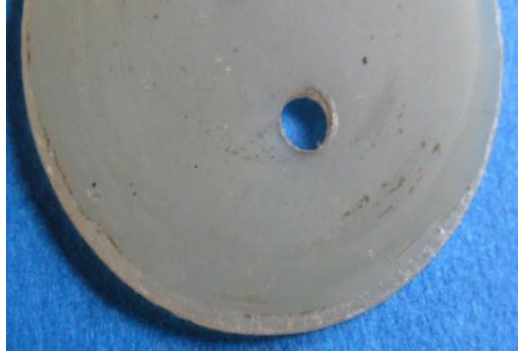

Figure 2. Photos of initial polycaproamide samples after friction (a); the same is for samples containing $\mathrm{HCF}_{2} \mathrm{CF}_{2} \mathrm{CH}_{2} \mathrm{OH}$ in amounts of $0.05 \% \mathrm{wt}$. (b), and the same is for samples containing $\mathrm{HCF}_{2} \mathrm{CF}_{2} \mathrm{CH}_{2} \mathrm{OH}$ in amounts of $0.005 \%$ [138].

Oligomeric fluoroalkanes $\mathrm{H}\left(\mathrm{CF}_{2}\right)_{n} \mathrm{Cl}(n=7-16)$ with molecular weight not exceeding 600 , which are by-products of polytetrafluoroethylene synthesis, have high antifriction properties, low melt viscosity combined with high thermal stability, processability and good solubility in organic solvents $[140,141]$. The introduction of organofluorine additives improves the wear resistance and thermofriction characteristics of elastomeric compositions, due to modification of rubber surface and migration of modifier to the surface.

Surface modification of elastomers by molecular fluorine, hydrofluorination by hydrogen

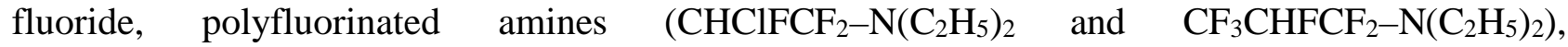
polyfluorinated organoboric acids, $N$-sulfonimide imides $\left(\mathrm{CF}_{3} \mathrm{SO}_{2} \mathrm{NFSO}_{2}-\mathrm{C}_{6} \mathrm{~F}_{13}\right.$ and $\left.\mathrm{CF}_{3} \mathrm{SO}_{2} \mathrm{NFSO}_{2}-\mathrm{C}_{4} \mathrm{~F}_{9}\right)$, metals fluorides with highest degree of oxidation $\left(\mathrm{CoF}_{3}, \mathrm{AgF}_{2}, \mathrm{MnF}_{3}, \mathrm{BiF}_{5}\right.$, $\mathrm{UF}_{6}, \mathrm{PbF}_{4}$ ), copolymerization with unsaturated fluoromonomers in the presence of poly- and perfluorinated peroxide initiators promotes the creation of hydrophobic surface layer enriched in fluorine, which favorably affects on increase of wear- and corrosion resistance of obtained materials $[2-15,88,92-94,142-151]$. 


\section{Polymer composite materials containing poly- and perfluorinated compounds immobilized at a carrier}

The immobilization of organofluorine compounds (including poly- and perfluorinated compounds) at highly dispersed inorganic carriers opens up new prospects for obtain of polymer composite materials with improved properties [88]. This method of introducing additives into macromolecular systems becomes especially relevant if the modifier is volatile or capable to fracture under temperature conditions of its combination with polymer melts, as well as if it is needed to introduce into polymers a small amounts of poly- and perfluorinated compounds.

Natural and synthetic montmorillonite, saponite, kaolin, vermiculite, hectorite and fluorohectorite, mica fluoride, graphite and fluorinated carbon nanotubes can be used as carriers [88, 152-157]. The greatest distribution (including industrial sale) was received the various marks of montmorillonite clays modified by organoelement compounds: Cloisite (Southern Clay Products, USA), Dellite (Laviosa Chimica Mineraria, Italy), Somasif (CBC Co., Japan) and Monamet (Metaclay, Karachev).

The layered aluminosilicate montmorillonite has not only a unique polyelement composition, but is also stratifiable in polymer matrix up to single monolayers with a thickness about $1 \mathrm{~nm}$ (see Figure 3) [152-160]. As a rule, its organoelement constituents are mono-, di-, triand tetraalkyl (aryl, aralkyl, alkoxy, aroxy) ammonium and phosphonium halides. The organoclays containing S- and N-containing compounds (sulfonamides), Si- and B-organic compounds, as well as drugs [151-164] are also of practical importance.

To obtain composites like "polymer/layered filler", the polymerization filling method, the solution method, melt mixing and sol-gel technology can be used [88, 154, 155, 161]. The possibility of improving a number of properties (physicomechanical, thermal resistance, reduced combustibility and gas permeability) has led to increase in use of layered polymer composite materials in a number of areas, such as automotive, consumer goods industry, electronics, aerospace industry (world suppliers of polymer composites containing organoclay, are Toyota, Bayer AG, Creanova, GE Plastics, Honeywell, Hyperion, Nanocor, General Motors and others) [152-167]. 


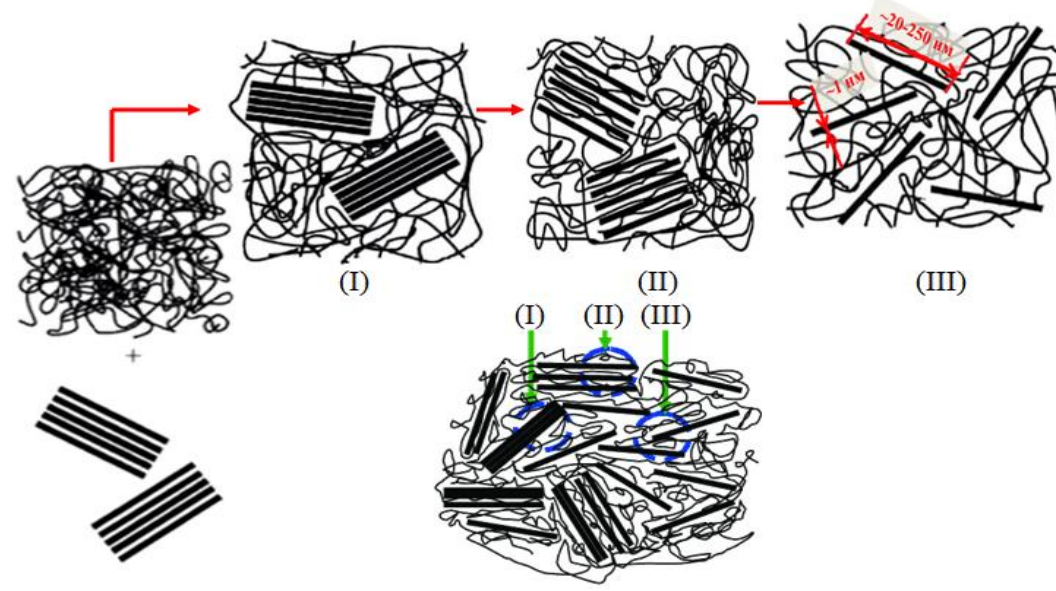

Figure 3. Formation of micro- and nanocomposite morphologies after introduction of montmorillonite clay into polymers: (I) microcomposite, (II) intercalated nanocomposite, (III) exfoliated nanocomposite.

There is only fragmentary information about immobilization of poly- and perfluorinated compounds on highly dispersed inorganic carriers [8, 88, 89, 141, 168-173], which describe the modification of layered fillers by fluoroalkanes $\mathrm{H}\left(\mathrm{CF}_{2}\right)_{n} \mathrm{Cl}(n=7-14)$, fluorinated acids ( including $\mathrm{H}_{2}\left[\mathrm{SiF}_{6}\right]$ ), their salts and ethers, ionic and nonionic fluorine-containing surfactants $\left(\left[\mathrm{R}_{\mathrm{F}} \mathrm{SO}_{2} \mathrm{NH}\left(\mathrm{CH}_{2}\right)_{n} \mathrm{NR}_{3}\right]^{+} \mathrm{X}^{-}, \mathrm{R}_{\mathrm{F}} \mathrm{SO}_{2} \mathrm{NH}_{2}\right)$. The work of Academician V. V. Korshak analyzes the specific feature of physicochemical processes occurring in the graphite/chloroperfluorododecyl fluorosulfate system (for example, [174]).

When processing of mineral fillers by fluoroalkanes, a modified product with "grafted" layer of fluoroalkane is formed (see Figure 4). The properties of heterochain polymers modified by $\mathrm{H}\left(\mathrm{CF}_{2}\right)_{n} \mathrm{Cl}$, immobilized at various substrates (bentonite, marble, travertine, tuff), are described in $[141,175-177]$.

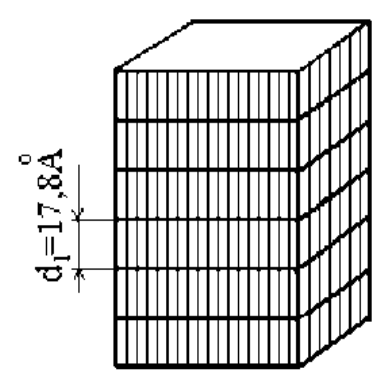

a

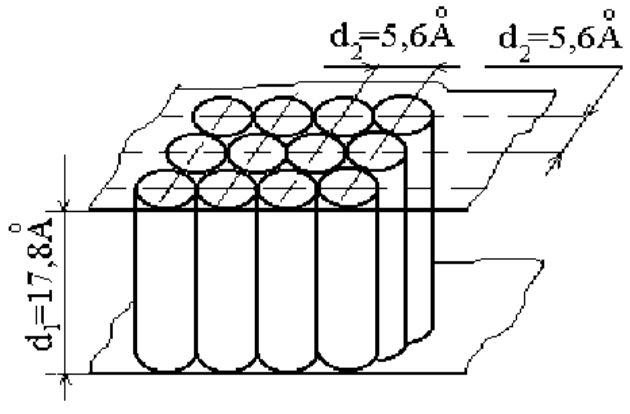

б

Figure 4. Diagram of the structure of fluoroalkane crystallite, consisting of their parallel layers (a) and one layer of fluoroalkane (b)).

Fluorinated montmorillonite has various uses [178-180], including use in dental practice, 
providing stepwise release of ions $\mathrm{F}^{-}$for effective prevention of dental caries [181, 182], as well as for preparation of barrier composite materials Nafion [183].

Modification of montmorillonite by fluorine-containing surfactants Flactonite $\mathrm{K}-76$ $\left(\mathrm{R}_{\mathrm{F}} \mathrm{SO}_{2} \mathrm{~A}\right.$, where $\mathrm{R}_{\mathrm{F}}-\mathrm{C}_{3} \mathrm{~F}_{7} \mathrm{O}\left(\mathrm{CF}_{2}-\mathrm{CF}\left(\mathrm{CF}_{3}\right) \mathrm{O}\right)_{n}, n=1-3$, or $\mathrm{R}_{\mathrm{F}}=\mathrm{XC}_{m} \mathrm{~F}_{2 m}$, where $\mathrm{X}=\mathrm{F}$ or $\mathrm{Cl}, m=3-$ 9, $\mathrm{Hal}=\mathrm{Cl}$ or $\left.\mathrm{J}, \mathrm{A}=-\mathrm{NH}\left(\mathrm{CH}_{2}\right)_{3} \mathrm{~N}^{+}\left(\mathrm{CH}_{3}\right)_{2} \mathrm{X}_{1} \mathrm{Hal}^{-}, \mathrm{X}_{1}=-\mathrm{CH}_{2} \mathrm{CH}_{2} \mathrm{OH}\right)$ act to raise the tribotechnical properties of resulting lubricants [184].

It should be noted that alternative way of introducing fluorinated compounds with low boiling points (for example, fluorinated alcohols, perfluoroketones $\mathrm{CF}_{3} \mathrm{CF}_{2} \mathrm{C}(=\mathrm{O}) \mathrm{CF}\left(\mathrm{CF}_{3}\right)_{2}$ ) into polymers is microencapsulating them in a shell (polyvinyl ethoxyorganosiloxane, polyvinyl alcohol with urea-resorzidine-formalde-formalde and montmorillonite, gelatin) [114, 185]. Microencapsulation of antipyrenes into silicon-containing shell gives higher thermal stability during molding in comparison with initial combustion retardants, preserves and increases their inhibitory properties, allowing the creation of materials with high fire retardant and physico-mechanical properties (see Table 25).

Table 25. Thermal stability and combustibility of polycaproamide with addition of $1 \mathrm{H}, 1 \mathrm{H}, 5 \mathrm{H}$ trihydroperfluoropentan-1-ol and antipyrene T-2 (technical mixture of ammonium salt of methylphosphonic acid amide and ammonium chloride), microencapsulated in a silicon-containing shell.

\begin{tabular}{|c|c|c|}
\hline Type of flame retardant & $\begin{array}{c}\text { Maximum decomposition rate, } \\
\mathrm{mg} / \mathrm{min}\end{array}$ & $\begin{array}{c}\text { Oxygen index, } \\
\% \text { vol. }\end{array}$ \\
\hline- & 8,9 & 20,0 \\
\hline Antipyrene T-2 & 5,6 & 29,3 \\
\hline
\end{tabular}

However, the permeability of shell complicates the full technical application of this method of introducing fluorinated compounds into polymers. The stabilization effect is possible as a result of the modification of microcapsule shell material by introducing into its composition (at the stage of shell formation) the nanoparticles of mineral lamellar filler - montmorillonite.

\section{Conclusions}

The unique structure (chemical, electronic, stereochemical) of poly- and perfluorinated compounds determines their influence on the state of supramolecular formations of polymer materials modified by them, reporting chemo-, thermo-, fire-, light-, wear-, bio- and hydrolytic stability and others useful properties, which leads to ever-increasing increase in a number of publications on fluoropolymer topics and release of fluorine-containing materials by leading worldwide companies. 
Modification of polymers by poly- and perfluorinated compounds can be carried out at the stages of their preparation, processing and surface modification of finished products, allowing to obtain cord-, textile-, medical-, industrial rubber- fluorinated materials with controlled hydrophobicity, as well as materials with special properties.

Uunique chemical structure of polyfluorinated alcohols $\mathrm{H}\left(\mathrm{CF}_{2} \mathrm{CF}_{2}\right)_{n} \mathrm{CH}_{2} \mathrm{OH}$, containing two proton-donor $\mathrm{HCF}_{2}-, \mathrm{HO}-$ and proton-acceptor $-\mathrm{CF}_{2}-\mathrm{CF}_{2}-$ groups in the molecule, determines the possibility of their physicochemical interaction with polymer macromolecules, promoting to reorganization of its supramolecular structure. At the same time, the positive changes in properties of modified polymer are observed in the case of introduction these additives with low concentrations $\left(10^{-3}-10^{-4} \%\right.$ wt.). However, the use of small amounts of polyfluorinated alcohols makes it difficult to uniformly distribute them throughout the polymer matrix, impossible of introducing directly into polymer melt due to their low boiling point and achieving the irreversible binding of alcohols with macromolecules.

Immobilization of poly- and perfluorinated compounds at highly dispersed inorganic carriers (primarily montmorillonite clay) allows not only to expand the possible methods of introducing these modifying additives (including their micro- and nanocolorities) into macromolecular systems, but also to provide a synergistic effect of fluorine-containing modifier, carrier and products of their interaction to formed structure of polymers modified by them to obtain multi-purpose composite materials with improved properties.

\section{References}

1. Fluoropolymer materials / N. A. Adamenko, E. N. Bolbasov, V. M. Buznik, S. Yu. Vavilova, S. V. Gnedenkov, V. I. Dyachenko, I. V. Zibareva, L. N. Ignatyeva, S. M. Igumnov, A. V. Kazurov, D. P. Kiryukhin, G. A. Kichigina, T. Yu. Kumeyeva, P. P. Kushch, D. V. Mashtalyar, O. A. Melnik, V. G. Nazarov, L. N. Nikitin, A. A. Okhlopkova, N. P. Prorokova, E. Yu. Safronova, S. A. Serov, S. L. Sinebryukhov, S. A. Sleptsova, V. I. Sokolov, V. P. Stolyarov, S. I. Tverdokhlebov, S. A. Khatipov, A. K. Tsvetnikov, E. Yu. Shits, A. B. Yaroslavtsev; Executive editor: V. M. Buznik; Institute of solution chemistry G. A. Krestov n.a., National Research Tomsk State University, FSUE "All-Russian Research Institute of Aviation Materials, Consortium "Fluoropolymer Materials and Nanotechnologies" - Tomsk: of Scientific and Technical Literature (LLC "NTL"). 2017, 596 p. (in Russian)

2. Scheirs, J. Modern Fluoropolymers: High Performance Polymers for Diverse Applications (Wiley Series in Polymer Science) / J. Scheirs. - Wiley. 1997, 660 p. 
3. Ameduri B., Boutevin B. Well Architectured Fluoropolymers: Synthesis, Properties and Applications. - Amsterdam: Elsevier, 2004, 508 p.

4. Ameduri, B. Fluorinated Polymers: Volume 1: Synthesis, Properties, Processing and Simulation (Rsc Polymer Chemistry) / B. Ameduri, H. Sawada, T. Narita. - Royal Society of Chemistry, RSC Publishing. 2016, 439 p.

5. Ameduri, B. Fluorinated Polymers: Volume 2: Applications (Polymer Chemistry Series) (Rsc Polymer Chemistry) / B. Ameduri, H. Sawada, T. Narita. - Royal Society of Chemistry, RSC Publishing. 2016. 396 p.

6. Buznik, V. M. The state of domestic chemistry of fluoropolymers and possible development prospects / V. M. Buznik // Ros. khim. zh. (Journal of Russian Chemical Society D.I. Mendeleev). 2008, 52(3), 7-12. (in Russian)

7. Smith, D. W. Handbook of Fluoropolymer Science and Technology / D. W. Smith, S. T. Iacono, S. S. Iyer. - John Wiley \& Sons, Inc., Hoboken, New Jersey. 2014, 646 p.

8. Ebnesajjad, S. Fluoropolymer Additives / S. Ebnesajjad, R. A. Morgan. - Elsevier. William Andrew. 2019, 304 p.

9. Hougham, G. G. Fluoropolymers 1: Synthesis (V. 1) / G. G. Hougham, P. E. Cassidy, K. Johns, T. Davidson. - Springer Science \& Business Media. 2006, 330 p.

10. Hougham, G. G. Fluoropolymers 2: Properties (Topics in Applied Chemistry) (V. 2) / G. G. Hougham, P. E. Cassidy, K. Johns, T. Davidson. - Springer Science \& Business Media. 1999,. 408 p.

11. Smith, D. W. Handbook of Fluoropolymer Science and Technology / D. W. Smith, S. T. Iacono, S. S. Iyer. - Wiley. 2014, 670 p.

12. Ebnesajjad, S. Fluoroplastics, Volume 1: Non-Melt Processible Fluoropolymers - The Definitive User's Guide and Data Book (Plastics Design Library) / S. Ebnesajjad. - Elsevier. William Andrew. 2014, 703 p.

13. Ebnesajjad, S. Fluoroplastics, Volume 2: Melt Processible Fluoropolymers - The Definitive User's Guide and Data Book (Plastics Design Library) / S. Ebnesajjad. Elsevier. - William Andrew. 2015, 766 p.

14. Ebnesajjad, S. Fluoropolymer Applications in the Chemical Processing Industries: The Definitive User's Guide and Handbook (Plastics Design Library) / S. Ebnesajjad, P. R. Khaladkar. Elsevier. William Andrew. 2017, 452 p.

15. Drobny, J. G. Technology of Fluoropolymers / J. G. Drobny. - CRC Press. Boca Raton, Florida. 2001, 172 p. 
16. Specific feature of hydrophobization of highly porous ceramic materials using fluoroligomers / A. S. Bespalov, N. I. Nefedov, I. S. Deev, E. V. Kurshev, S. L. Lonskij, V. M. Buznik. Proceedings of VIAM. 2019, 5(77), 41-51. (in Russian)

17. Assortment, properties and application of fluoropolymers of Kirov-Chepetsk Chemical Plant / Z. L. Baskin, D. A. Shabalin, E. S. Vyrazhejkin, S. A. Dedov // Ros. khim. zh. (Journal of Russian Chemical Society D.I. Mendeleev). 2008, 52(3), 13-23. (in Russian)

18. Kochetkova, G. V. New brands of domestic fluororubbers / G. V. Kochetkova, B. A. Loginov // Ros. khim. zh. (Journal of Russian Chemical Society D.I. Mendeleev). 2008, 52(3), 23-25. (in Russian)

19. Perepelkin, K. E. Fluoropolymer fibers: the physicochemical nature and structural conditionality of their unique properties, production and application features / K. E. Perepelkin // Chemical fibers. 2004, 1, 39-50. (in Russian)

20. Fluoropolymers // Ed. Walla L.A., Translate from English, Ed. Knunyants I.L., Ponomarenko V.A.. Moscow: Publishing house"Mir", 1975, 448 p. (in Russian)

21. Panshin Yu.A., S. G. Malkevich, Dunaevskaya C. S.,Ftoroplasts - Leningrad: "Khimia". 1978, 232 p. (in Russian)

22. Industrial organofluorine products: Handbook. / Ed. Maksimova B. N. - Leningrad: "Khimia". 1990, 464 p. (in Russian)

23. Ponomarenko, V. A., Krukovsky S. P., Alybina A. Yu. Fluorine-containing hetero-chain polymers - Moscow .: "Nauka", 1973, 304 p. (in Russian)

24. Malichenko B.F., Fluorinated polyamides and polyurethanes - Kiev: "Naukova Dumka".1977, 231 p. (in Russian)

25. Gitina, R. M. Polycondensation reactions of fluorinated organic compounds / R. M. Gitina, E. L. Zajceva, A. Ya. Yakubovich // Uspekhi khimii. 1971, 40(8), 1479-1510. (in Russian)

26. Knunyanc, I. L. Linear polyfluorinated bifunctional compounds of the same name as potential monomers / I. L. Knunyanc, Li Chzhi-Yuan', V. V. Shokina // Uspekhi khimii. 1963, 32(9), 1052-1086. (in Russian)

27. Berson, K. A. Fluorine-containing organic polymers / K. A. Berson, K. R. Patrik // Uspekhi khimii. 1964, 33(8), 977-990. (in Russian)

28. Malichenko, B. F. Fluorine-containing polyesters and polythioethers / B. V. Malichenko // Uspekhi khimii. 1971, 40(3), 547-571. (in Russian)

29. Gardiner J. Fluoropolymers: Origin, Production, and Industrial and Commercial Applications / J. Gardiner // Australian Journal of Chemistry. 2015. V. 68. P. 13-22. 
30. Buznik, V. M. Fluoropolymer materials: application in the oil and gas complex (Series "Academic Readings", vol. 61) / Moscow: "Neft I Gas", Russian State University of Oil and Gas. I.M. Gubkin. 2009, 31 p. (in Russian)

31. Hatipov, S. A. Influence of ionizing radiation on the structure of polytetrafluoroethylene. Destruction or cross-linking?/ S. A. Hatipov, V. M. Buznik. LAP LAMBERT Academic Publishing. 2018, 84 p. (in Russian)

32. Istomin, N. P. Antifriction properties of composite materials based on fluoropolymers / N. P. Istomin, A. P. Semenov. - M.: "Nauka", 1981, 147 p. (in Russian)

33. Knunyanc, I. L. Subjugation of the impregnable element,Moscow: of the USSR Academy of Sciences. 1963, 192 p. (in Russian)

34. Fokin A. V.,Semenov A. P., Application of fluoroorganic compounds in technology,Moscow: IMASH RAS. 1999, 70 p. (in Russian)

35. Knunyanc, I. L. Synthesis of fluoroorganic compounds / I. L. Knunyanc, G. G. Yakobson. M.: "Khimiya". 1973, 312 p. (in Russian)

36. Knunyanc, I. L. Synthesis of fluoroorganic compounds (monomers and intermediates) / I. L. Knunyanc, G. G. Yakobson. - M.: "Khimiya". 1977, 304 p. (in Russian)

37. Rahimov, A. I. Chemistry and technology of fluoroorganic compounds / A. I. Rahimov. - M.: "Khimiya". 1986, 271 p. (in Russian)

38. Isikava, N. Fluorine Compounds. Synthesis and application / N. Isikava; Transl. M. V. Pospelova, Ed. A. V. Fokin. - M.: "Mir". 1990, 407 p. (in Russian)

39. Furin, G. G. Modern methods of fluorination of organic compounds / G. G. Furin.-M.: "Nauka". 2000, 240 p. (in Russian)

40. Electronic structure of fluoroorganic compounds / G. G. Furin, A. V. Zubrev, L. N. Mazalov, V. D. Yumatov. - Novosibirsk: "Nauka", 1988, 157 p. (in Russian)

41. Igumnov, S. M. Synthesis of fluoroorganic compounds (part 1-4) / S. M. Igumnov, E. V. Igumnova. M.: SIA "P\&M-Invest", 2011-2019. (in Russian)

42. Knunyanc, I. L. New data on the reactions of fluoroorganic compounds / I. L. Knunyanc, V. R. Polishchuk // Uspekhi khimii. 1976, 45(7), 1139-1176. (in Russian)

43. Knunyanc, I. L. Success in the synthesis and research of fluoroorganic compounds / I. L. Knunyanc, V. R. Polishchuk // Uspekhi khimii. 1975, 44(4), 685-714. (in Russian)

44. Aleksandrova T. M.,Sletkina, L. S., Rogovin Z. A., Synthesis and properties of grafted copolymers of cellulose and wool keratin with vinyl esters of fluorocarboxylic acids // Journal of Applied Chemistry. 1972, 9, 2038-2042. (in Russian) 
45. Peculiarities of the structure of copper- and nickel-fluoropolymer composites fabricated by explosive pressing / L. N. Ignatieva, G. A. Zverev, N. A. Adamenko, A.V. Kazurov, I. V. Sergeev, A. Yu. Ustinov, I. A. Tkachenko, V. M. Bouznik // Journal of Fluorine Chemistry. 2015, 172, 68-73.

46. Rakhimov, A. I. Initiators for Manufacture of PVC / A. I. Rakhimov. - N. Y., 2008, 182 p.

47. Reaction of singlet difluorocarbene with 6-methylpyrimidin-4(3H)-one derivatives / A. I. Rakhimov, I. Yu. Kameneva, M. B. Navrotsky, E. S. Titova,S. V. Kudashev // Russian Journal of General Chemistry. 2008, 78(5), 971-972.

48. Study of interaction of complex HF. $\mathrm{BF}_{3}$-catalyst with p-methylstyrene AB INITIO method / V. A. Babkin, D. S. Andreev, A. V. Ignatov, V. S. Belousova, A. N. Liberovskaya, A. V. Kozhuhova, E. S. Titova, A. I. Rahimov, N. A. Rahimova, V. T. Fomichev, Fluorine notes, 2020, 1(128), 1-2, http://en.notes.fluorine1.ru/public/2020/1_2020/article_1.html (access date: 1.04.2020). 49. Synthesis and characterization of the fluorinated acrylic latex: Effect of fluorine-containing surfactant on properties of the latex film / W. Yang, Y. Chen, D. Han, L. Zhu // Journal of Fluorine Chemistry. 2013, 149, 8-12.

50. Quantum-chemical study of the protonation mechanism of p-fluorostyrene by the MNDO method / V. A. Babkin, Yu. A. Vashuta, A. V. Kozhuhova, D. S. Andreev, A. V. Ignatov, A. P. Knyazev, A. I. Rahimov, E. S. Titova, V. S. Belousova, A. R. Denisyuk, K. Yu. Prochuhan, O. S. Rahimova, Fluorine notes, 2019, 4(125), 5-6, http://en.notes.fluorine1.ru/ public/2019/4_2019/article_3.html (access date: 01.04.2020).

51. Fluorine influence on pharmaceuticalactivity of thiouracil derivatives / E. S. Titova, P. M. Vasil'ev, A. I. Rahimov, V. V. Vorfolomeeva, L. R. Yanalieva, Fluorine notes, 2016, 2(105), 5-6, http://en.notes.fluorine1.ru/public/2016/2_2016/letters/letter3.html (access date: 1.04.2020).

52. Catalytic synthesis of polyfluoroalkylchloroformiates / A. I. Rahimov, L. A. Butkovskaya, N. A. Rahimova, Fluorine notes, 2016, 1(104), 5-6. http://en.notes.fluorine1.ru/ public/2016/1_2016/letters/letter3.html (access date: 1.04.2020).

53. Schofield, H. Fluorine chemistry statistics: numbers of organofluorine compounds and publications associated with fluorine chemistry / H. Schofield // Journal of Fluorine Chemistry. 1999, 100(1-2), 7-11.

54. The market of fluoropolymers in Russia - 2020, Indicators and forecasts / Tebiz Group. 2020 (march), 136 p. https://tebiz.ru/mi/rynok-ftorpolimerov-v-rossii. (in Russian)

55. European market of fluoropolymers. Current situation and forecast 2020-2024/ ACG (Alto Consulting Group). 2020 (march), 115 p. https://alto-group.ru/otchot/mir/2331-evropejskij-rynokftorpolimerov-tekuschaja-situacija-i-prognoz-2020-2024-gg.html. (in Russian) 
56. Buznik, V. M. Bibliometric analysis of scientific publications on fluoropolymers / V. M. Buznik, I. V. Zibareva // Polymer Science. Series A. 2011, 53(11), 1110-1120.

57. Fluorine chemistry in Russia: bibliometrical and subject analysis / V. M. Buznik, I. V. Zibareva // Fluorine notes, 2015, 3(100), 1-2. http://en.notes.fluorine1.ru/public/ 2015/3_2015/retro/index.html.

58. Organofluorine chemistry: Promising growth areas and challenges / L.V. Politanskaya, G. A. Selivanova, E. V. Panteleeva, E. V. Tretyakov, V. E. Platonov, P. V. Nikul'Shin, A. S. Vinogradov, Y. V. Zonov, V. M. Karpov, T. V. Mezhenkova, V. V. Bardin, D. O. Prima, A. G. Makarov, A. V. Zibarev, A. V. Vasilyev, A. B. Koldobskii, O. S. Shilova, S. M. Morozova, A. A. Tyutyunov, V. E. Boiko et al. // Russian Chemical Reviews. 2019, 88(5), 425-569.

59. Andrienko O.S., Sachkov V.I., Yanovsky V.A, Practical methods for introducing fluorine into organic compounds / Tomsk: NTL Publishing House, 2010, 176 p. (in Russian)

60. Furin, G. G. Synthesis and Application of Fluorine-Containing Ethers Based on Perfluoroolefins / Chemistry for Sustainable Development. 2006, 14, 303-318.

61. Park, J. D. The Synthesis of Special Fluorine-Fontaining Monomers / J. D. Park. - Tapa blanda, 1966. $426 \mathrm{p}$.

62. Grampel, Robert D. Surfaces of fluorinated polymer systems / Robert D. van de Grampel. Eindhoven: Technische Universiteit Eindhoven, 2002, 151 p.

63. Rauscher, W. H. The Synthesis of Ethyl Adipamate and 2-Keto-6,6dihydroperfluorohexamethylenimine/ W. H. Rauscher, H. Tucker // Journal of the American Chemical Societ. 1954, 76, 3599-3601.

64. Synthesis and properties of the $\varepsilon$-aminocaproic acid polyfluorinated oligomers / A. V. Miroshnichenko, A. I. Rahimov, N. A. Rahimova // Fluorine notes, 2016, N 4(107), 3-4, http://en.notes.fluorine1.ru/public/2016/4_2016/letters/letter2.html (access date: 1.04.2020).

65. A quantum-chemical analysis of the mechanism of the reaction between 1,1,5trihydroperfluoropentanol and $\varepsilon$-caprolactam / N. A. Storozhakova, A. I. Rakhimov, E. Y. Efanova, R. G. Fedunov // Russian Journal of Physical Chemistry A. 2002, 76(12), 2026-2029.

66. Reactions of Polyfluorinated Telomeric Alcohols with $\varepsilon$-Caprolactam / N. A. Storozhakova, E. Yu. Efanova, A. I. Rakhimov // Russian Journal of Applied Chemistry. 2002. 75(10), 1715-1717. 67. Storozhakova N. A., Nalesnaya A. V., Rakhimov A. I., Prokshits V. N., Polyfluoroalkylation of $\varepsilon$-aminocaproic acid oligomers // Izvestiya of Volgograd State Technical University. Ser. "Chemistry and technology of organoelement monomers and polymeric materials": Interuniversity collection of scientific articles / VolGTU, Volgograd. 2004, 1(2), 117-120. (in Russian) 
68. Oligomerization and polymerization of $\varepsilon$-caprolactam in the presence of the system 1,1,5trihydroperfluoropentanol-acetic acid / N. A. Storozhakova, Kh. Kh. N. Akhmed, A. I. Rakhimov, R. G. Fedunov // Russian Journal of Applied Chemistry. 2007, 80(5), 813-817.

69. Modification of Polycaproamide by 1,1,5-Trihydroperfluoropentanol / I. A. Novakov, N. A. Storozhakova, A. P. Krasnov, V. B. Ivanov, V. V. Priymak // Polymer Science. Ser.B. 2005, 47(11-12), 335-338.

70. Synthesis of aliphatic polyamide bearing fluorinated groups from $\varepsilon$-caprolactam and modified cyclic lysine / D. Tunc, B. Améduri, C. Jérôme, P. Desbois, P. Lecomte, S. Carlotti // European Polymer Journal. 2015, 71, 575-584.

71. Surface Control of Thermosetting Fluorinated Polyurethane / D. Cai, Y. Ren, Y. Li, X. Wang // MATEC Web of Conferences (CMPSE 2017). 2017, 130, 1-4.

72. Ho, T. A new fluorinated polyurethane: Polymerization, characterization, and mechanical properties / T. Ho, K. J. Wynne // Macromolecules. 1992, 25(13), 3521-3527.

73. Kim, H. A study for mechanical and platelet adhesion properties of fluorinated polyurethanes / H. Kim // Polymer Korea. 2001, 25(3), 343-348.

74. Groult, H. Modern Synthesis Processes and Reactivity of Fluorinated Compounds / H. Groult, F. Leroux, A. Tressaud. - Elsevier. 2016, 792 p.

75. Smirnova, O. Fluorinated Polyurethanes, Synthesis and Properties / O. Smirnova, A. Glazkov, A. Yarosh, A. Sakharov // Molecules. 2016, 21(7), 1-10.

76. Fluorinated polyurethane based on liquid fluorine elastomer (LFH) synthesis via two-step method: the critical value of thermal resistance and mechanical properties / N. Li, F. Zeng, Y. Wang, D. Qu, W. Hu, Y. Luan, S. Dong, J. Zhang, Y. Bai // RSC Advances. 2017, 49, 30970-30978.

77. Low Surface Energy Polymeric Films from Novel Fluorinated Blocked Isocyanates / L. van Ravenstein, W. Ming, R. D. van de Grampel, R. van der Linde, G. de With, T. Loontjens, P. C. Thune, J. W. Niemantsverdriet // Macromolecules. 2004, 37 408-413.

78. $\mathrm{Wu}, \mathrm{Z}$. Synthesis and properties of fluorinated non-isocyanate polyurethanes coatings with good hydrophobic and oleophobic properties / Z. Wu, L. Tang, J. Dai, J. Qu // Journal of Coatings Technology and Research. 2019, 16, 1233-1241.

79. Blocked isocyanates: from analytical and experimental considerations to non-polyurethane applications / M. S. Rolph, A. L. J. Markowska, C. N. Warriner, R. K. O'Reilly // Polymer Chemistry. 2016, 7, 7351-7364. 
80. Pylnov D. V., Polyurethane elastomers based on polyfunctional oligoisoprenes and telechelate oligomers with fluorinated derivatives of diphenylolmethane: Abst. dis.,- Volgograd, 2013, 24 p. (in Russian)

81. Titova E. N., Development of filled polyurethane compositions modified with organofluorine surface-active compounds: Abst. dis.,-- Volgograd, 2012, 24 p. (in Russian)

82. Gugina, S. Yu. Use of fluorinated ethers of glycerol and 1,1,7-trihydroperfluoroheptanol for developing elastomers with improved technical and operation characteristics / S. Yu. Gugina, V. P. Medvedev // Russian Journal of Applied Chemistry. - 2014, 87(8), 1133-1139.

83. Rakhimova N. A. , Kudashev S. V., Synthesis of N-polyfluoroalkyl derivatives of glycerol mono- $\varepsilon$-aminocaproate - new polyfunctional polymer modifiers // Izvestiya of Volgograd State Technical University. Series "Chemistry and Technology of Organoelement Monomers and Polymer Materials",vol. 8: Intercollegiate. Sat scientific Art. / VolgSTU - Volgograd, 2011, 2, 145-150. (in Russian)

84. Kudashev, S. V. The effect of polyfluorinated modifiers on the structure and properties of heterochain polymers: Abst. dis. - Volgograd, 2011, 24 p. (in Russian)

85. Patent 2451048 RU, IPK C09D175/08, C09D175/14, C09D109/00. Composition for sports flooring / A. V. Nistratov, S. V. Kudashev, S. Yu. Gugina, A. I. Rahimov, N. A. Rahimova, I. A. Novakov; VolgGTU. - 2012.

86. Rakhimova N. A. Features of reactions of phthalic anhydride with polyfluorinated alcohols / N. A. Rakhimova, S. V. Kudashev // Russian Journal of General Chemistry. 2011, 81(7), $1529-1534$.

87. Patent 2451050 RU, IPK C09D175/14, C09D109/00. Composition for sports flooring / A. V. Nistratov, S. V. Kudashev, S. YU. Gugina, A. I. Rahimov, N. A. Rahimova, I. A. Novakov; VolgGTU. - 2012.

88. Kudashev, S.V. Composite materials based on high molecular weight compounds and dispersed systems of organic and organomineral nature / S. V. Kudashev, V. F. Zheltobryuhov, T. I. Danilenko; VolgGTU. - Volgograd, 2015, 144 p. (in Russian)

89. Kudashev, S.V. Polyethylene terephthalate: features of modification, structure and directions of recycling / S. V. Kudashev, V. F. Zheltobryuhov, T. I. Danilenko; VolgGTU. - Volgograd, 2014, 147 p. (in Russian)

90. Prorokova N.P., Buznik V.M., Modification of synthetic fibrous materials using fluoropolymers // Polymer materials and technologies. 2017, 3(2), 6-17. (in Russian) 
91. Hydrophobization of Polyester Textile Materials with Telomeric Tetrafl uoroethylene Solutions / N. P. Prorokova, T. Yu. Kumeeva, D. P. Kiryukhin, V. M. Buznik // Russian Journal of Applied Chemistry. 2013, 86(1), 69-75.

92. Kharitonov, A. P. Surface modification of polymers by direct fluorination: A convenient approach to improve commercial properties of polymeric articles / A. P. Kharitonov, L. N. Kharitonova // Pure and Applied Chemistry. 2009, 81(3), 451-471.

93. Pinson, J. Surface Modification of Polymers: Methods and Applications / J. Pinson, D. Thiry. - Wiley. 2019, 460 p.

94. Nazarov, V. G. Surface modification of polymers / V. G. Nazarov. - M.: MGUP, 2008, 474 p. (in Russian)

95. About fluorine-containing surface-active substances capable to modify polymer fabrics' fibers / A. A. Ageev, I. V. Aksyonova, V. A. Volkov, A. F. Eleev // Fluorine notes, 2012, 4(83), 5-6. http://en.notes.fluorine1.ru/public/2012/4_2012/letters/letter3.html.

96. Pugachev A. K., From the history of the creation of domestic fluoropolymers// Ros. khim. zh. (Journal of Russian Chemical Society D.I. Mendeleev). 2008, 52(3), 5-6. (in Russian)

97. Experience in the use of fluoropolymer materials in aircraft engineering / E. Ya. Bejder, A. A. Donskoj, G. F. Zhelezina, E. K. Kondrashov, Yu. V. Sytyj, E. G. Surnin // Ros. khim. zh. (Journal of Russian Chemical Society D.I. Mendeleev). 2008, 52(3), 30-44. (in Russian)

98. Nazarov, V. G. Fluorinated rubbers with improved tribotechnical properties / V. G. Nazarov, V. P. Stolyarov, V. A. Baranov, L. A. Evlampieva // Ros. khim. zh. (Journal of Russian Chemical Society D.I. Mendeleev). 2008, 52(3), 45-55. (in Russian)

99. Influence of the Composition of Graft Copolymers of Fluoroalkyl Methacrylates on Stability of the Superhydrophobic State of Stainless Steel Surface / V. V. Klimov, E. V. Bryuzgin, V. O. Kharlamov, A.D. Grudanova, A.V. Navrotsky, I. A. Novakov // Polymer Science, Series B. 2019, 61(6), 725-734.

100. Nikitin, L. N. Supercritical carbon dioxide as an active medium for chemical processes involving fluoropolymers / L. N. Nikitin, M. O. Gallyamov, E. E. Said-Galiev, A. R. Hohlov, V. M. Buznik // Ros. khim. zh. (Journal of Russian Chemical Society D.I. Mendeleev). 2008, 52(3), 5665. (in Russian)

101. Kiryuhin, D. P. Radiation-chemical synthesis of tetrafluoroethylene telomers and their use for creating thin protective fluoropolymer coatings / D. P. Kiryuhin, I. P. Kim, V. M. Buznik, L. N. Ignat'eva, V. G. Kuryavyj, S. G. Saharov // Ros. khim. zh. (Journal of Russian Chemical Society D.I. Mendeleev). 2008, 52(3), 66-72. (in Russian) 
102. Sevast'yanov, V. I. Plasma-chemical modification of fluorocarbon polymers to create new hemocompatible materials / V. I. Sevast'yanov, V. N. Vasilec // Ros. khim. zh. (Journal of Russian Chemical Society D.I. Mendeleev). 2008, 52(3), 72-8.. (in Russian)

103. Mujdinov, M. R. Development of methods for the synthesis of surface-modified fluoropolymer-containing composite materials / M. R. Mujdinov // Ros. khim. zh. (Journal of Russian Chemical Society D.I. Mendeleev). 2008, 52(3), 81-89. (in Russian)

104. Hatipov, S. A. Creation of a new antifriction and sealing material based on radiation-modified polytetrafluoroethylene / S. A. Hatipov, N. A. Artamonov // Ros. khim. zh. (Journal of Russian Chemical Society D.I. Mendeleev). 2008, 52(3), 89-97. (in Russian)

105. Haritonov, A. P. Direct fluorination of polymer products - from basic research to practical use / A. P. Haritonov, B. A. Loginov // Ros. khim. zh. (Journal of Russian Chemical Society D.I. Mendeleev). 2008, 52(3), 106-111. (in Russian)

106. Gricenko, K. P. Films of polytetrafluoroethylene deposited by evaporation in a vacuum: growth mechanism, properties, application / K. P. Gricenko // Ros. khim. zh. (Journal of Russian Chemical Society D.I. Mendeleev). 2008, 52(3), 112-123. (in Russian)

107. Yampol'skij, Yu. P. Amorphous perfluorinated membrane materials: structure, properties and application / Yu. P. Yampol'skij // Ros. khim. zh. (Journal of Russian Chemical Society D.I. Mendeleev). 2008, 52(3), 123-130. (in Russian)

108. Buznik, V. M. Morphology and structure of micron and nanosized polytetrafluoroethylene powders obtained by the gas-phase method / V. M. Buznik, V. G. Kuryavyj // Ros. khim. zh. (Journal of Russian Chemical Society D.I. Mendeleev). 2008, 52(3), 131-139. (in Russian)

109. Kumeeva, T. Yu. Superhydrophobization of polyester textile materials by surface modification with polytetrafluoroethylene: Abst. dis., Ivanovo, 2010,17 p. (in Russian)

110. Kichigina G. A., Kushch P. P., Kiryukhin D. P., Prorokova N. P., Use of radiationsynthesized tetrafluoroethylene telomers with silane end groups for hydrophobization of polyester fabric// High Energy Chemistry, 2020., 54(2), 135-141. (in Russian)

111. Prorokova, N. P. Improving the wettability of polyester fabric with using direct fluorination // N. P. Prorokova, T. Yu. Kumeeva, S.Y. Vavilova // Journal of Fluorine Chemistry. 2019, 219, 115-122.

112. Chapurina, M. A. Surface energy of polyester and viscose fibres modified with polyfluoroalkyl acrylates / M. A. Chapurina, L. S. Gal'Braikh, L. V. Redina, N. V. Kolokolkina // Fibre Chemistry. 2019, 219, 115-122. 
113. Chapurina, M. A. New fluorine-containing polymers for modification of the surface properties of chemical fibres / M. A. Chapurina, L. S. Gal'braikh, L.V. Redina, L. S. Sletkina, S. M. Igumnov, E. Yu. Maksareva, K. E. Narinyan // Fibre Chemistry. 2005, 37(2), 81-83.

114. Sletkina, L. S. Modification of the surface of chemical fibers with fluorine-containing copolymers / L. S. Sletkina, L. V. Redina, N. V. Kolokolkina // Khimicheskie volokna. 1995, 5, 27-30. (in Russian)

115. Novakov I. A., Rakhimova N. A., Polycaproamide systems with polyfluorinated fragments // Bulletin of Volgograd State Technical University, Series "Chemistry and Technology of Organoelement Monomers and Polymer Materials". Vol. 6: Intercollegiate. Sat scientific Art. / VolgSTU,- Volgograd, 2009, 2, 5-29. (in Russian)

116. Storozhakova, N. A. Graft Polymerization of Octafluoropentyl Acrilate to Polycaproamide Thread / N. A. Storozhakova, V. A. Korotkov, A. I. Rakhimov, T. I. Danilenko // Method and Theory in Physical Organic Chemistry. - N.Y., 2005, 45-49.

117. Storozhakova, N. A. Radical Grafting of Octafluoropentyl Acrylate to a Polycaproamide Thread / N. A. Storozhakova, V. A. Korotkov, A. I. Rakhimov, T. I. Danilenko // Russian Journal of Applied Chemistry. 2004, 77 (1), 141-143.

118. Miroshnichenko A.V., Rakhimov A.I., Vostrikova O.V., Features of the interaction of polyfluoroalkylchlorosulfites with carboxylic acids and their salts // Bulletin of Volgograd State Technical University, Ser. "Chemistry and technology of organoelement monomers and polymeric materials",- Volgograd, 2019, 5(228), 37-41. (in Russian)

119. Rakhimov A. I., Miroshnichenko A. V., Vostrikova O. V., Features of the polyfluoroalkylation of phenols with polyfluoroalkylchlorosulfites // Bulletin of Volgograd State Technical University, Ser. "Chemistry and technology of organoelement monomers and polymeric materials", - Volgograd, 2017, 4(199), 20-21. (in Russian)

120. Rakhimov A. I., Miroshnichenko A. V., Vostrikova O. V., Features of the polyfluoroalkylation of phenols with polyfluoroalkylchlorosulfites // Bulletin of Volgograd State Technical University, Ser. "Chemistry and technology of organoelement monomers and polymeric materials",- Volgograd, 2015, 4(159), 12-14. (in Russian)

121. Avilova V. S., Petrosyan E. V., Maryshev A. Yu., Rakhimova N. A., Rakhimov A. I., Modification of oxidized isotactic polypropylene by polyfluoroalkylchlorosulfite // Bulletin of Volgograd State Technical University, Series "Chemistry and Technology of Organoelement Monomers and Polymer Materials", Vol. 12: Interuniversity collection of scientific articles / VolgSTU, - Volgograd, 2014, 7(134), 120-121. (in Russian) 
122. Features of phenyl ethers formation using polyfluoroalkyl chlorosulfites / A. I. Rahimov, A. V. Miroshnichenko // Fluorine notes, 2011, 6(79), 3-4. http://en.notes.fluorine1.ru/public/2011/ 6_2011/letters/index.html.

123. The influence of substituents in allyl alcohol on the reaction with polyfluoroalkylchlorosulphites / A. I. Rahimov, G. I. Nikishin, A. V. Miroshnichenko, Fyong Thao Do Zyong // Fluorine notes, 2011, 5(78), 3-4. http://en.notes.fluorine1.ru/public/2011/5_2011/ letters/index.html.

124. Rakhimov A. I., Nalesnaya A. V., Vostrikova O. V., Rakhimova N. A., Babushkin A. S., Reactions of carboxyl-containing compounds and their salts with polyfluoroalkyl sulfites // Bulletin of Volgograd State Technical University, Series "Chemistry and Technology of Organoelement Monomers and Polymer Materials", vol. 6: Interuniversity collection of scientific articles / VolgSTU,- Volgograd, 2009, 2, 30-32. (in Russian)

125. Miroshnichenko A.V., Rakhimov A.I., Vostrikova O.V., Features of the interaction of polyfluoroalkylchlorosulfites with carboxylic acids and their salts // Bulletin of Volgograd State Technical University, Ser. "Chemistry and technology of organoelement monomers and polymeric materials",- Volgograd, 2019, 5(228), 37-41. (in Russian)

126. Rakhimov A. I., Miroshnichenko A. V., Vostrikova O. V., Features of the polyfluoroalkylation of phenols with polyfluoroalkylchlorosulfites // Bulletin of Volgograd State Technical University, Ser. "Chemistry and technology of organoelement monomers and polymeric materials",- Volgograd, 2017, 4(199), 20-21. (in Russian)

127. Preparation and properties of polyfluorinated acrylamide-sodium acrylate copolymers / A. I. Rakhimov, D. A. Vershinin, A. V. Miroshnichenko, O. S. Rakhimova // Russian Journal of General Chemistry. 2013, 83(6), 1043-1046.

128. Rakhimov, A. I. A New Method for Preparing Polyfluorinated Ethers / A. I. Rakhimov, A.V. Nalesnaya, O. V. Vostrikova // Russian Journal of General Chemistry. 2004, 74(4), 633-634.

129. Rakhimov A. I., Miroshnichenko A. V., Vostrikova O. V., Effect of the Association of Polyfluorinated Alcohols with a Catalyst on the Reaction of the Formation of Polyfluoroalkyl Chlorosulfites // Bulletin of Volgograd State Technical University, Ser. "Chemistry and technology of organoelement monomers and polymeric materials",-- Volgograd, 2016, 12(191), 70-73. (in Russian)

130. Rakhimov A. I., Miroshnichenko A. V., Vostrikova O. V., Quantum-chemical analysis of the catalytic reaction of the formation of polyfluoroalkylchlorosulfites // Bulletin of Volgograd State Technical University, Ser. "Chemistry and technology of organoelement monomers and polymeric materials", - Volgograd, 2016, 4(183), 77-80. (in Russian) 
131. New reaction of polyfluorinated alcohols with thionyl chloride / A. I. Rahimov, A. V. Miroshnichenko // Fluorine notes, 2011, 3(76), 1-2. http://en.notes.fluorine1.ru/public/2011/ 3_2011/letters/index.html.

132. Rakhimova N. A., Moldavskaya E. D., Rakhimov A. I., Avilova V. S., Modification of oligomeric wastes of polycaproamide production / // Bulletin of Volgograd State Technical University, Series "Chemistry and Technology of Organoelement Monomers and Polymer Materials", Vol. 10: Intercollegiate. Sat. scientific Art. / VolgSTU Volgograd, 2013, 4(107), 97-99. (in Russian)

133. Patent 2430883 RU, IPK S01V33/44. Method of modifying of montmorillonite / N. A. Rahimova, S. V. Kudashev; GOU VPO VolgGTU. - 2011.

134. Rakhimova N. A., Moldavskaya E. D., Rakhimov A. I., Miroshnichenko A. V., Isolation, identification and polyfluoroalkoholysis of oligomers from polycaproamide production wastes // Bulletin of Volgograd State Technical University. Series "Chemistry and Technology of Organoelement Monomers and Polymer Materials", vol. 8: Interuniversity collection of scientific articles / VolgSTU - Volgograd, 2011, 2, 97-99. (in Russian)

135. Fisechko R.V., Regularities of the synthesis of ethers based on polyfluoroalkylchlorosulfites: Abstract. dis. - Volgograd, 2007, 20 p. (in Russian)

136. Patent 2433142 RU, IPK C08F8/32, C08C19/22, C08F4/32, B01J31/04, C07D223/10. Method of producing prepolymer with terminal amino groups / I. A. Novakov, N. A. Rahimova, S. V. Kudashev; GOU VPO VolgGTU. - 2011.

137. Furin G. G., Ilyin A. A., Ivanova L. M., Bakhmutov Yu. L., Ilyin A. N., Prospects for the use of new materials based on fluorine-containing alcohols in the automotive industry // Chemistry for sustainable development. 2005, 13(6), 831-838. (in Russian)

138. Krasnov A. P., Rakhimova N. A., Zubavichus Ya. V., Naumkin A. V., Bazhenova V. B., Afonicheva O V., Kudashev S. V., Novakov I. A., Study of the structure and surface properties of poly-e-caproamide modified with polyfluorinated alcohols during friction // Friction and lubrication in machines and mechanisms, 2011, 2, 29-35. (in Russian)

139. Novakov I. A., Krasnov A. P., Rakhimova N. A., Bazhenova V. B., Afonicheva O. V., Mit V. A., Naumkin A.V., Kosenkova S.A., Effect of polyfluoroalkyl ethers of $\varepsilon$-aminocaproic acid oligomers on the tribochemical properties of poly- $\varepsilon$-caproamide // Bulletin of Volgograd State Technical University, Series "Chemistry and Technology of Organoelement Monomers and Polymer Materials", vol. 5: Interuniversity collection of scientific articles / VolgSTU - Volgograd, 2008, 1, 125-129. (in Russian) 
140. Patent 2237690 RU, IPK C08L77/00. Polymeric composition for antifriction material / A. P. Krasnov, I. A. Rashkovan, M. E. Kazakov, O. V. Afonicheva, I. L. Ajzinson, O. B. Kulachinskaya; INEOS RAS, SPC "UVIKOM" LLC (Carbon fibers and composites) - 2004. (in Russian)

141. Karapetyan A. N., Gribova I. A., Krasnov A. P., Studnev Yu. N., Poghosyan A. K., Oganesyan K. V., Study of the structure and properties of Armenian minerals modified with fluorine-containing oligomers // Bulletin of NAS RA and SIUA. Ser. TN. 2005, 58(2), 243-250. (in Russian)

142. Friction of rubber containing organofluoric modifier / A. P. Krasnov, O. V. Afonicheva, Yu. N. Studnev, V. M. Andryushin, V. A. Mit, I. O. Volkov, V. K. Komornitskii-Kuznetsov, O. B. Kupriyanovich, T. I. Paskhin, V. S. Yurovksii, Y. N. Studnev // Journal of Friction and Wear. 2000, 21(3), 100-103.

143. Moore, A. L. Fluoroelastomers Handbook: The Definitive User's Guide and Databook / A. L. Moore, J. G. Drobny. - Taylor \& Francis. 2006, 359 p.

144. Banerjee, S. Handbook of Specialty Fluorinated Polymers / S. Banerjee. - William Andrew. 2015, $340 \mathrm{p}$.

145. Nudelman Z. N., Fluoroelastomers: fundamentals, processing, application / - Moscow: PIF RIAS, 2007, 383 p. (in Russian)

146. Galil-Ogly, F. A. Fluororubber and rubber based on them / F. A. Galil-Ogly, A. S. Novikov, Z. N. Nudel'man. - Moscow: "Khimia", 1966, 234 p. (in Russian)

147. Novickaya, S. P. Fluoroelastomers / S. P. Novickaya, Z. N. Nudel'man, A. A. Doncov. Moscow: "Khimia", 1988, 240 p. (in Russian)

148. Chapurkin, V. V. Vulcanization of fluoroelastomers using fluorine peroxides / V. V. Chapurkin, V. P. Medvedev, S. V. CHapurkin // Russian Journal of Applied Chemistry. 2015, 88(8), 1282-1287.

149. Chapurkin, V. V. Features of the structure formation of fluoroelastomers by fluoroperoxides / V. V. Chapurkin, V. P. Medvedev, S. V. Chapurkin // International Polymer Science and Technology. 2016, 43(2), 37-39..

150. Nistratov A. V., Physicochemical principles for the development of formulations and technology of compositions based on oligothiols, oligodienes and oligoesters used to produce polymeric materials with improved technical and operational characteristics: Abstract. dis., Volgograd, 2014, 48 p. (in Russian)

151. Clemitson, I. R. Castable Polyurethane Elastomers / I. R. Clemitson. - CRC Press (Taylor \& Francis Group). 2015, 272 p. 
152. Thomas, S. Polyurethane Polymers: Composites and Nanocomposites / S. Thomas, J. Datta, J. Haponiuk et al. - Elsevier. Amsterdam, Netherlands. 2017, 634 p.

153. Galimberti, M. Rubber-Clay Nanocomposites. Science, Technology, and Applications / M. Galimberti. - John Wiley \& Sons Limited. 2011, 627 p.

154. Utracki L. A. Clay-Containing Nanocomposites V. 1, 2. - Rapra Technology Limited, UK, 2004.

155. Mai, Y. Polymer nanocomposites / ed. Y. Mai, Z. Yu - Cambridge: Woodhead, 2006, 594 p. 156. Fabrication and characterization of fluorinated single-walled carbon nanotubes / A. V. Krestinin, Yu. M. Shul'Ga, E. I. Knerel'Man, G. I. Zvereva, M. B. Kislov, V. M. Martynenko, I. I. Korobov, G. I. Davydova, A. P. Kharitonov, O. M. Zhigalina, V. G. Zhigalina, N. A. Kiselev, M. Dubois, M. M. Brzhezinskaya, A. S. Vinogradov, A. B. Preobrazhenskii // Nanotechnologies in Russia. 2009, 4(1-2), 60-78.

157. Morgan, A. B. Flame Retardant Polymer Nanocomposites / A. B. Morgan, C. A. Wilkie. Wiley-Interscience. New Jersey. 2007, 451 p.

158. Wolfson S. I., Okhotina N. A., Nigmatullina A. I., Sabirov R. K., Idiyatullina G. Kh., Composite polymer materials based on polyolefins, elastomers and layered nanofillers . - Kazan: Publishing house "Fən" of Tatarstan Republic Academy of Science, 2013, 167 p. (in Russian)

159. New approaches to the development of hybrid nanocomposites: From structural materials to high-tech applications / V. A .Gerasin, V. V. Karbushev, G. P. Karpacheva, R. V. Talroze, Y. V. Kudryavtsev, E. M. Antipov, V. G. Kulichikhin // Russian Chemical Reviews. 2013, 82(4), 303-332.

160. Pomogailo, A. D. Hybrid polymer-inorganic nanocomposites / A. D. Pomogailo // Russian Chemical Reviews. 2000, 69(1), 53-80.

161. Polymer-silicate nanocomposites: physicochemical aspects in situ polymerization / S. N. Chvalun, L. A. Novokshonova, A. P. Korobko, P. N. Brevnov // Ros. khim. zh. (Journal of Russian Chemical Society D.I. Mendeleev). 2008, 52(5), 52-57. (in Russian)

162. Golubeva, O. Yu. Hydrothermal synthesis of magnesium silicate montmorillonite for polymer-clay nanocomposites / O. Yu. Golubeva, E. N. Korytkova, V. V. Gusarov // Russian Journal of Applied Chemistry. 2005, 78(1), 26-32.

163. Hybrid nanostructures based on layered silicates and nitrogen-containing organic compounds / O. Yu. Golubeva, O. S. Domanova, V. L. Ugolkov, V. V. Gusarov // Russian Journal of General Chemistry. 2007, 77(2), 221-225.

164. Nanocomposite hydrocolloid adhesives for biomedical applications // Russian Nanotechnologies, 2006, 1(1-2), 170-182. (in Russian) 
165. Patent 2699109 RU, IPK C08J5/16, C08L27/18, C08K3/22, C08K3/34. Polymer tribotechnical material based on polytetrafluoroethylene, mechanically activated kaolin and magnesium spinel / E. A. S. Laukkanen, P. N. Tarasova, S. A. Slepcova, N. N. Lazareva, A. A. Ohlopkova, A. A. D'yakonov; Ammosov Northeast Federal University. - 2019.

166. Okhlopkova, A. A. Influence of the structure of polytetrafluoroethylene-based nanocomposites on their tribotechnical characteristics / A. A. Okhlopkova, P. N. Petrova, A. G. Parnikova // Journal of Friction and Wear. 2009, 30(6), 425-430.

167. Khashirova S. Yu., Begiev M. B, Tsurova A. T., Ligidov M. Kh., Mikitaev A. K., Structure and properties of composites based on polyamide- 6 and modified organoclay // Plasticheskie massy. 2019, 1-2, 40-43. (in Russian)

168. Impact of fluorine containing schungite on the properties of polymer composition materials / N. A. Rahimova, V. P. Medvedev, T. A. Kurilenko, V. S. Avilova, A. A. Okolelova, A. I. Rahimov // Fluorine notes, 2015, 4(101), 5-6. http://en.notes.fluorine1.ru/public/2015/4_2015/ letters/letter3.html.

169. Rakhimova, N. A. Hydrophobic and organophilic properties of polyfluoroalkyl-oligo-ecaproamide as a $\mathrm{Na}^{+}$-montmorillonite modifier / N. A. Rakhimova, S. V. Kudashev // Russian Journal of General Chemistry. 2011, 81(2), 369-373.

170. Modification of $\mathrm{Na}^{+}$-montmorillonite with mono- and bis(polyfluoroalkyl) phthalates / S. V. Kudashev, V. F. Zheltobryukhov, O. A. Barkovskaya, V. M. Dronova, K. R. Shevchenko // Russian Journal of Applied Chemistry. 2013, 86(7), 1010-1015.

171. The impact of tracial 1.1.3-trihydroperfluoropropanol-1 on tribological properties of poly- $\varepsilon$ caproamide filled with $\mathrm{Na}^{+}$-montmorillonite and graphite / I. A. Novakov, N. A. Rahimova, A. P. Krasnov, Ya. V. Zubavichus, S. V. Kudashev // Fluorine notes, 2011, N 1(74), 1-2. http://www.notes.fluorine1.ru/public/2011/1_2011/letters/rusletter1.html.

172. Novakov I. A., Rakhimova N. A., Krasnov A. P., Zheltobryukhov V. F., Naumkin A. V., Kudashev S. V., Tribochemical and tribotechnical properties of new fluorine-containing guest-host graphite composites / // Bulletin of Volgograd State Technical University. Series "Chemistry and Technology of Organoelement Monomers and Polymer Materials", vol. 9: Intercollegiate. Sat scientific Art. / VolgSTU - Volgograd, 2012, 5, 183-188.

173. Novakov I. A., Rakhimova N. A., Krasnov A. P., Naumkin A. V., Zubavichus Y. V., Kudashev S. V., X-ray photoelectronic study of graphite modified with 1,1,3trihydroperfluoropropanol-1, and its effect on the tribological characteristics of poly- $\varepsilon$-caproamide // Izv. Volgograd State Technical University. Series "Chemistry and Technology of Organoelement 
Monomers and Polymer Materials", vol. 8: Interuniversity collection of scientific articles / VolgSTU - Volgograd,2011, 2, 140-145.

174. Korshak, V. V. On the nature of the interaction in a graphite - chloroperfluorododecyl fluorosulfate mixture under mechanical action / V. V. Korshak, A. V. Fokin, I. A. Gribova, A. P. Krasnov, Yu. N. Studnev // Dokl. AN SSSR. 1987, 296(5), 1157-1159.

175. Karapetyan A.N., Tribological properties of self-lubricating composites based on hetero-chain polymers // Bulletin NAS RA and SIUA, Ser. TN. 2004, 57(1), 58-62. (in Russian)

176. Karapetyan A. N., Poghosyan A. K., Oganesyan K. V., Gribova I. A., Krasnov A. P., Studnev Yu. N., Study of the structure and properties of modified minerals// Bulletin of Polotsk State University, Series C: Fundamental sciences. 2007, 9, 147-150. (in Russian)

177. Karapetyan A. N., Research of surface films during friction of composite self-lubricating materials based on hetero-chain polymers // Bulletin NAS RA and SIUA. Ser. TN. 2004, 57(2), 233-237. (in Russian)

178. New fluorinated montmorillonites for the preparation of UV-cured coatings / D. Gianni, R. Bongiovanni, L. Conzatti, S. Turri // Journal of Colloid and Interface Science. 2009, 336(2), 455-461.

179. Fluorine Route Synthesis of Montmorillonites Containing Mg or $\mathrm{Zn}$ and Characterization by XRD, Thermal Analysis, MAS NMR, and EXAFS Spectroscopy / M. Reinholdt, J. Miehé Brendlé, L. Delmotte, M. H. Tuilier, R. le Dred, R. Cortès, A. M. Flank // European Journal of Inorganic Chemistry. 2001, 11, 2831-2841.

180. Synthesis and characterization of montmorillonite-type phyllosilicates in a fluoride medium / M. Reinholdt, J. Miehé-Brendlé, L. Delmotte, R. Le Dred, M.-H. Tuilier // Clay Minerals. 2005, 40(2), 177-190.

181. Fluorinated Montmorillonite Composite Resin as a Dental Pit and Fissure Sealant / K.-Y. Li, C.-C. Tsai, C.-H. Fang, Y.-L. Wang, F.-H. Lin, C.-P. Lin // Polymers. 2019, 11, 10(1535), 1-14.

182. Fluorinated Montmorillonite and 3YSZ as the Inorganic Fillers in Fluoride-Releasing and Rechargeable Dental Composition Resin / K.-Y. Li, C.-C. Tsai, T.-C. Lin, Y.-L. Wang, F.-H. Lin, C.-P. Lin // Polymers. 2020, 12, 1(223), 1-14.

183. Improvement of the barrier properties of Nafion (R) by fluoro-modified montmorillonite / J.M. Thomassin, C. Pagnoulle, D. Bizzari, G. Caldarella // Solid State Ionics. 2006, 177(13), 1137-1144.

184. Patent 2194742 RU, IPK C10M141/08. Antiwear and antifriction additive with friction modifier, lubricating material, and method of preparing friction modifier / A. G. Aptekman, V. I. Beklemyshev, V. Yu. Bolgov, I. I. Mahonin; LLC "Tribotechnology Laboratory". - 2002. 
185. Novel microencapsulated liquid fire extinguishers with a nanomodified microcapsule shell / A. D. Vilesov, O. M. Suvorova, V. E. Yudin, N. N. Saprykina, M. S. Vilesova, R. P. Stankevich // Polymer Science. Series B. 2014, 56(4), 512-519. 